\title{
Method of Ultrasonic Nanocrystal Surface Modification for Improvement of Surface Characteristics of Aisi D2 Heat-Treated With Different Tempering Conditions
}

\section{Seung Yeong Cho}

Korea Maritime and Ocean University

Do-Sik Shim ( $\nabla$ think@kmou.ac.kr)

Korea Maritime and Ocean University

\section{Research Article}

Keywords: Ultrasonic nanocrystal surface modification, Tool Steel, Heat-Treatment, Hardness, Surface Roughness

Posted Date: June 4th, 2021

DOl: https://doi.org/10.21203/rs.3.rs-546540/v1

License: (c) (1) This work is licensed under a Creative Commons Attribution 4.0 International License. Read Full License 


\title{
Method of ultrasonic nanocrystal surface modification for improvement of surface characteristics of AISI D2 heat-treated with different tempering conditions
}

\author{
Seung Yeong Cho ${ }^{1,2}$ and Do Sik Shim ${ }^{1,2, 凶}$ \\ ${ }^{1}$ Department of Ocean Advanced Materials Convergence Engineering, Korea Maritime and Ocean University, Busan 49112, \\ Republic of Korea \\ ${ }^{2}$ Interdisciplinary Major of Ocean Renewable Energy Engineering, Korea Maritime and Ocean University, Busan 49112, \\ Republic of Korea \\ Corresponding author: think@kmou.ac.kr, Tel: +82 10_4844_4455
}

\section{$\underline{\text { Abstract }}$}

AISI D2, an alloy tool steel, has been widely used as a cold-work die steel because of its excellent wear resistance, toughness, and machinability. However, when it is used as a mold or tool under a high load, high hardness and wear resistance are required to improve its service life. This study aimed to apply ultrasonic nanocrystal surface modification (UNSM), a local surface hardening technology, to the surface of D2 steel. To maximize the surface improvement effect achievable through UNSM, it is important to select the optimal process conditions according to the characteristics of the base metal. Therefore, the effects of UNSM were compared for different initial hardness values of D2 in this study. To this end, the base metal was subjected to different heat treatment conditions to exhibit different hardness values (approximately 40, 45, 50, and $55 \mathrm{HRc}$ ). Changes in the surface of the base metal were observed according to the three main parameters of the UNSM process: the load, inter-pass interval, and feed rate. No significant changes in the surface roughness and hardness was caused by the feed rate. As the inter-pass interval of UNSM decreased and the static load increased, the surface roughness of the base metal increased. However, the specimen with low initial hardness (D2-H40), the roughness improvement decreased as the load increased. On the other hand, the surface hardness improvement increased as the inter-pass interval decreased and the load increased regardless of the initial hardness of the base metal. It also was found that the specimen with the highest initial hardness (D2-H55) exhibited the greatest hardness improvement rate of $8.7 \%$ and smallest hardened layer thickness of $220 \mu \mathrm{m}$. In addition, the largest compressive residual stress $(-1,130.6 \mathrm{MPa})$ was formed on the surface of D2-H55 after UNSM, which occurred because the base metal with high initial hardness had limited plastic flow due to fine grains and low ductility, causing thus the energy repeatedly delivered 
by UNSM to be concentrated in a limited area. Consequently, reducing the inter-pass interval is effective on improving the surface roughness and hardness regardless of the material hardness. However, the load must be applied at an appropriate level, depending on the material hardness. Therefore, when D2 is heat-treated and used according to the product requirements, it will be effective to consider the changes after UNSM treatment based on hardness after heat treatment that were derived in this study.

Keywords: Ultrasonic nanocrystal surface modification, Tool Steel, Heat-Treatment, Hardness, Surface Roughness

\section{Introduction}

AISI D2 or simply D2 is a tool steel that has been widely used as a high-carbon, high-chromium alloy steel. It has been employed in various industries owing to its excellent toughness and wear resistance and has mainly been utilized as a cold-work tool steel, such as in cutting tools, forming rolls, and dies for press. Therefore, it is necessary to improve the mechanical characteristics and fatigue lives of coldwork tool steels to be used as parts and dies [1]. In general, the mechanical and microstructural characteristics of metallic materials are improved by heat treatment. D2 has excellent quenching performance due to the addition of molybdenum and vanadium and can exhibit a high hardness of more than $58 \mathrm{HRc}$ when processed by normalizing (at $500-530{ }^{\circ} \mathrm{C}$ ). In addition, heat treatment makes the microstructure finer and increases the wear resistance by generating martensitic structures. Therefore, the mechanical characteristics can be controlled by varying the heat-treatment conditions according to the product requirements.

However, cold-work dies and tools are exposed to environments that make them vulnerable to fatigue cracking due to repeated friction. To address this problem, surface hardening studies have been conducted. Surface hardening is a post-treatment process that increases the hardness and wear resistance and maintains the toughness of the material. Surface hardening is mainly divided into chemical surface hardening, which changes the chemical composition, and physical surface hardening, which does not change the chemical composition. Chemical surface hardening includes nitriding, in which steel is heated in ammonia gas over an extended period of time to form a nitride layer [2-6], and carburizing, in which carbon penetrates the metal surface [5-7]. Physical surface hardening includes metal spraying, in which molten metals are attached to a surface by spraying them with compressed air $[8,9]$; induction hardening, in which a surface is hardened using high-frequency current and coolant 
injection [10]; and shot peening, in which the surface layer is hardened by injecting metals at high speed [11-21]. For D2 steel, physical surface hardening methods, such as shot peening and laser shock peening, have mainly been used.

In shot peening, a type of cold working, $0.5-0.1 \mathrm{~mm}$ metal shot balls strike the metal surface through high-speed airflow. A thin plastically deformed layer is formed on the surface through repeated impacts. In such a deformed layer, compressive residual stress is produced. Compressive residual stress extends the fatigue life by offsetting the tension under repeated tensile loads. Shot peening includes hot shot peening, which is performed near the austenite or martensite transformation temperature, and a water jet in which water is injected at a high speed for processing. Lee et al. [11] applied shot peening to SCM920, a material for automotive gears, and confirmed an improvement in wear resistance. Kim et al. applied shot peening to aluminum alloys and verified that compressive residual stress improved the fatigue life [12]. Cheong et al. observed changes in the hardness of spring steel SPS 5A specimens with different hardness values by varying the shot peening parameters [13]. In addition, the surface and mechanical characteristics have been improved using shot peening in many studies [14-17]. However, shot peening has low precision because it is impossible to adjust the positions of the injected metal balls accurately. In addition, the shot balls used cause environmental pollution. Studies on peening to address these shortcomings have been conducted.

Laser shock peening is a method of hardening by transferring the energy of a high-power laser beam to the material surface in the form of heat and shock waves, and it can also produce the self-quenching effect. This technology generates structures with high hardness values and prevents thermal deformation and stress. Laser shock peening uses 30-300 $\mu \mathrm{m}$ laser spots, thereby enabling finer and more precise processing than shot peening [18]. Kim et al. improved the surface and mechanical characteristics of high-strength titanium alloys using laser peening technology [19]. Yang et al. observed the compressive residual stress and hardness of SM45C according to the power of a yttriumaluminum-garnet laser. They reported that irregular surfaces and tensile residual stress were produced when the laser power was not appropriate but that the appropriate laser power improved the surface and produced compressive residual stress [20]. Laser shock peening technology, however, requires a robot dedicated to laser beam irradiation, and thermal deformation of the material may occur owing to plasma exposure [21].

In this study, surface hardening using ultrasonic nanocrystal surface modification (UNSM) was 
investigated. UNSM is a technology that modifies a surface crystalline structure using ultrasonic vibration energy. It is more precise and eco-friendly than shot peening and more economical than laser shock peening. In addition, many studies have verified that UNSM technology improves the surface roughness, wear resistance, and fatigue strength of metal. Lee et al. confirmed the possibility of extending the service lives of press dies through wear tests [22]. Moreover, Cho et al. improved the surface characteristics of an aluminum alloy, AlSi10Mg, produced by direct metal laser sintering through the application of UNSM, and Kheradmandfard et al. utilized UNSM to improve the surface hardness of the titanium-niobium-tantalum-zirconium alloy $[1,23]$. Thus, many studies have been conducted to improve the surface and mechanical characteristics of various materials by applying UNSM technology [24-26]. Among them, there have been research cases in which UNSM has been applied to D2 steel. Amanov et al. applied UNSM treatment to D2 steel at $500{ }^{\circ} \mathrm{C}$ and confirmed an improvement in performance [27]. Pyun et al. analyzed the effects of the number and direction of UNSM treatment on the surface and mechanical characteristics of D2 and observed the surface changes between before and after heat treatment [28].

However, there have been no studies in which UNSM technology has been applied after varying the initial hardness of D2 and the surface and mechanical characteristics have been compared. D2 has been used as a tool steel in various fields owing to its numerous benefits, as described above. In particular, the hardness and toughness of D2 steel can be controlled under different heat treatment conditions, depending on the product requirements. UNSM can be applied to heat-treated D2 for further improvement. In this case, UNSM causes different changes depending on the characteristics of D2 after heat treatment. Therefore, this study focused on the changes caused by UNSM depending on the process conditions and initial hardness of the D2 base metal. D2 specimens were prepared by applying different tempering temperature conditions after quenching. UNSM was then applied to the D2 specimens using the load, inter-pass interval, and feed rate, among the UNSM process conditions, as parameters. After UNSM treatment, changes in the surface roughness and hardness of the specimens were observed. To analyze the causes of the property changes, the microstructures of the specimens were observed and the compressive residual stress was examined. 


\section{Experimental procedure}

\subsection{Specimen preparation}

The base metal used in this study was AISI D2, an alloy tool steel commonly used for cold pressing. Table 1. describes the chemical composition of the D2 base metal. This material has excellent wear resistance and toughness owing to its high carbon content. In addition, it can have various characteristics following heat treatment owing to the addition of molybdenum and vanadium. Thus, it is mainly hardened by quenching and tempering treatment. Fig. 1. presents the detailed heat treatment conditions utilized in this study. Firstly, quenching was performed by heating D2 to the austenitizing temperature and then rapidly cooling it after a certain period of time. In the quenching process, D2 was heated to $1,010^{\circ} \mathrm{C}$ after preheating it twice to 650 and $850^{\circ} \mathrm{C}$. After heating, $\mathrm{N}_{2}$ cooling was performed in a vacuum furnace. The tempering process in which heating and cooling were performed at temperature below the transformation point $\left(723^{\circ} \mathrm{C}\right)$ was then implemented to remove the brittleness and internal stress resulting from quenching. In this instance, the hardness and toughness of the base metal were determined by the tempering temperature. The hardness decreased as the tempering temperature increased, whereas it increased as the tempering temperature decreased. In this study, tempering was performed at $620,600,580$, and $560{ }^{\circ} \mathrm{C}$. The tempering process in which cooling was performed after maintaining the tempering temperature for $2 \mathrm{~h}$ was repeated three times. The hardness of the base metal was varied by changing the tempering temperature, and the changes in the characteristics of each base metal after UNSM treatment were observed.

Table 1 Chemical composition of AISI D2 (unit: wt \%)

\begin{tabular}{|c|c|c|c|c|c|c|c|c|c|c|}
\hline Material & $\mathrm{C}$ & $\mathrm{Si}$ & $\mathrm{Mn}$ & $\mathrm{P}$ & $\mathrm{S}$ & $\mathrm{Ni}$ & $\mathrm{Cr}$ & $\mathrm{Mo}$ & $\mathrm{Cu}$ & $\mathrm{V}$ \\
\hline AISI D2 & 1.46 & 0.26 & 0.44 & 0.26 & 0.001 & 0.20 & 11.56 & 0.83 & 0.14 & 0.22 \\
\hline
\end{tabular}




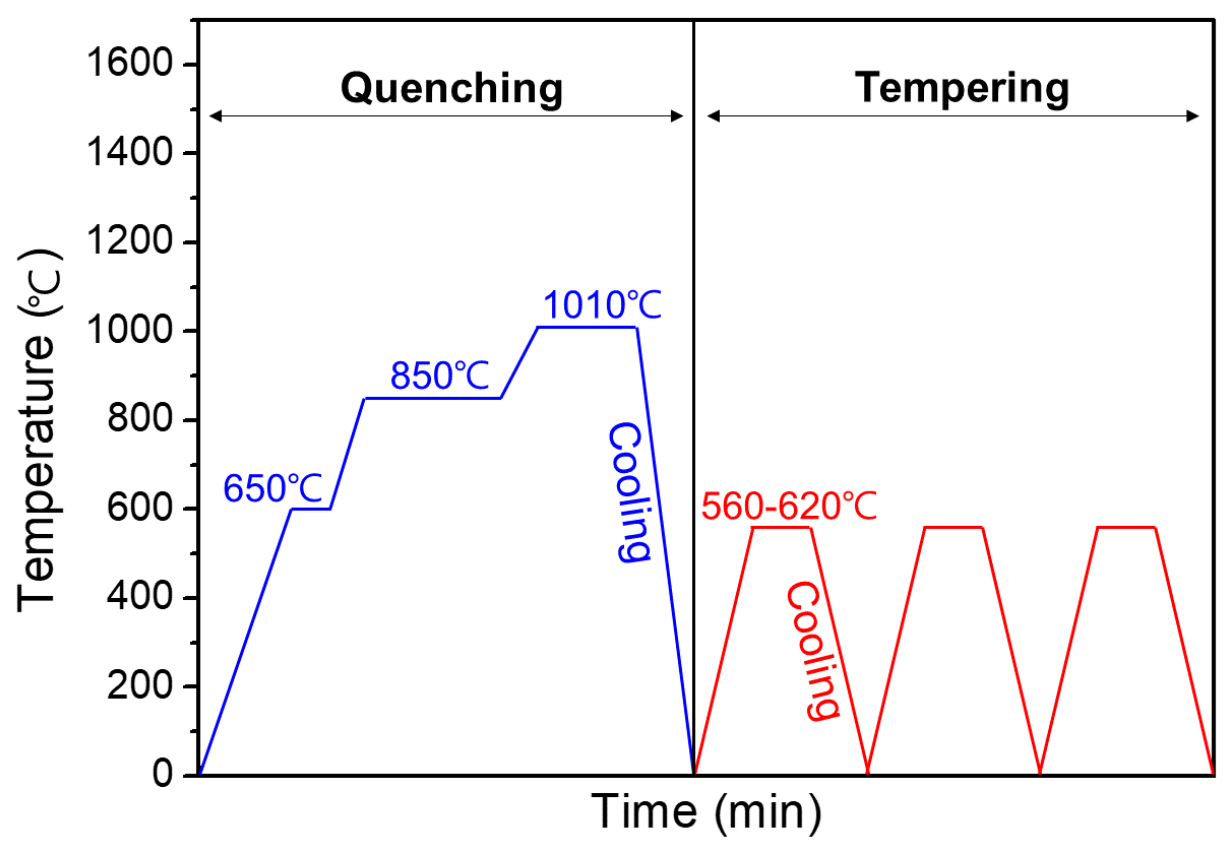

Fig. 1 Schematic representation of heat-treatment process for D2

\subsection{UNSM}

UNSM induces severe plastic deformation on the material (or component) surface by causing tens of thousands of collisions per second with an amplitude of several $\mu m$ using ultrasonic vibration energy. It can refine the microstructure of a material to a certain depth from its surface and create regular microdimples on the surface. The refined structure improves the wear resistance and impact resistance by enhancing the hardness, compressive residual stress, and wear and fatigue characteristics.

Fig. 2. shows a schematic diagram and the application of UNSM to the material surface. The static load is controlled with weights, and ultrasonic waves of a certain frequency are generated by the ultrasonic oscillator. The generated ultrasonic waves are used when the transducer and booster devices deliver a load to an indenter, on which a ball tip of WC material $(1,700 \mathrm{HV})$ is attached. Here, the delivered load corresponds to the static load of the weights combined with the dynamic load resulting from the vibration energy of the ultrasonic waves. Because the UNSM device is installed on a numerical control/computer numerical control $(\mathrm{NC} / \mathrm{CNC})$ machine tool, precise processing of the surface is possible.

Based on previous work, a ball tip diameter $d$ of $2.38 \mathrm{~mm}$, an amplitude $A$ of $30 \mathrm{kHz}$, and a 
frequency $f$ of $30 \mu \mathrm{m}$ were set as fixed parameters in this study. The other main parameters, that is, the static load, inter-pass interval, and feed rate, were varied to analyze the effects of UNSM on heattreated D2. Table 2. lists the fixed parameter values, and Table 3. summarizes the strain energy densities calculated under each condition. In each case, UNSM was applied once to the top surface of the D2 base metal with dimensions of $10 \mathrm{~mm} \times 50 \mathrm{~mm}$ (Fig. 3).
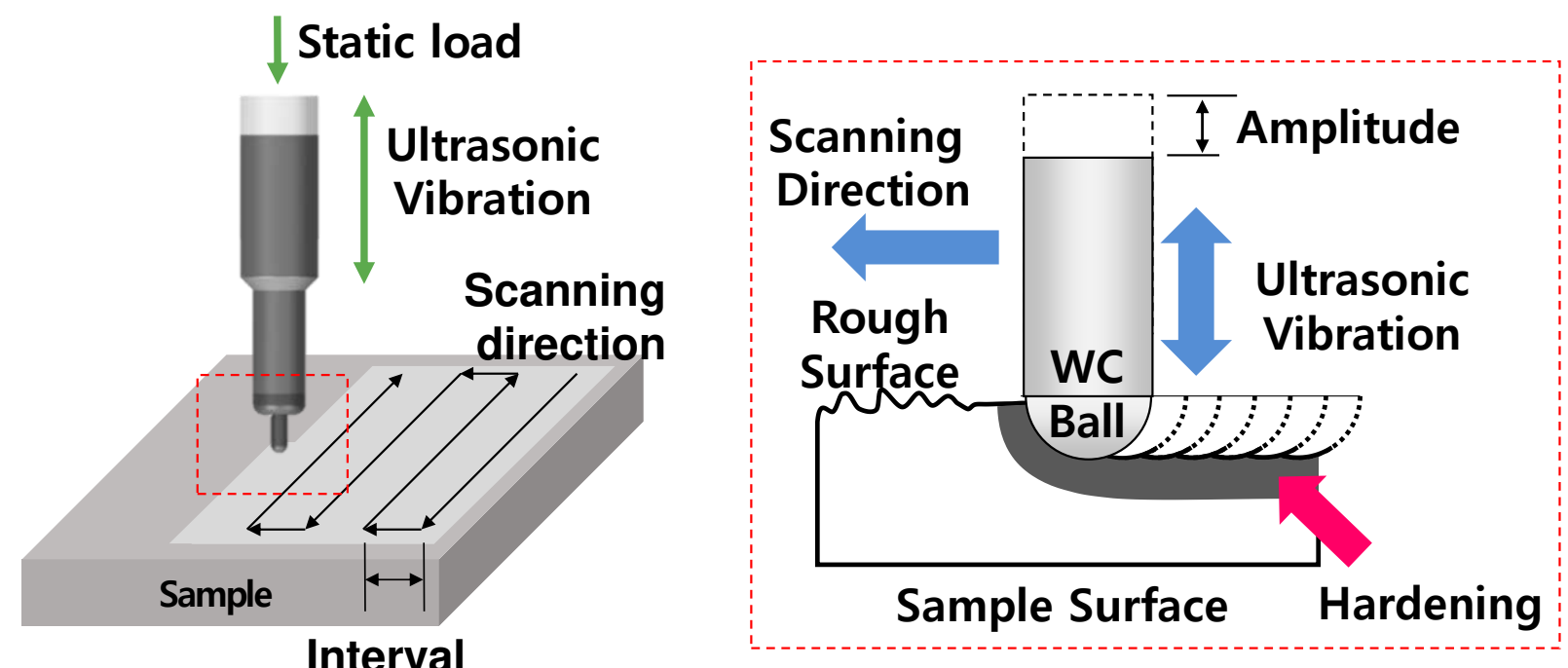

Fig. 2 Schematics of the (a) UNSM experimental setup, and (b) UNSM principles

Table 2 Experimental conditions of UNSM

\begin{tabular}{|c|c|c|}
\hline \multirow{4}{*}{$\begin{array}{c}\text { Fixed } \\
\text { parameters }\end{array}$} & Ball tip diameter $\boldsymbol{d}(\mathbf{m m})$ & 2.38 \\
\cline { 2 - 3 } & Amplitude $\boldsymbol{A}(\boldsymbol{\mu m})$ & 30 \\
\cline { 2 - 3 } & Ultrasonic frequency $\boldsymbol{f}(\mathbf{k H z})$ & 30 \\
\hline \multirow{2}{*}{$\begin{array}{c}\text { Control } \\
\text { parameters }\end{array}$} & Scanning speed $\boldsymbol{v}(\mathbf{m m} / \mathbf{m i n})$ & $1000 / 2000 / 3000$ \\
\cline { 2 - 3 } & Static Load $\boldsymbol{F}(\mathbf{N})$ & $10 / 30 / 50$ \\
\hline Interval $\boldsymbol{s}(\boldsymbol{\mu m})$ & $10 / 50 / 90$ \\
\hline Number of impact per unit area $\left(\mathbf{m m}^{2}\right)$ & $N=(60 \times f) /(v \times s)$ \\
\hline \multicolumn{2}{|c|}{ Strain energy density $E\left(J / \mathrm{mm}^{2}\right)=F \times N \times(A / d)$} \\
\hline
\end{tabular}


Table 3 Control parameters and calculated strain energy densities

\begin{tabular}{|c|c|c|c|c|}
\hline & $\begin{array}{c}\text { Static load } \\
(\mathbf{N})\end{array}$ & $\begin{array}{c}\text { Inter-pass interval } \\
(\boldsymbol{\mu} \mathbf{m})\end{array}$ & $\begin{array}{c}\text { Feed rate } \\
(\mathbf{m m} / \mathbf{m i n})\end{array}$ & $\begin{array}{c}\text { Strain energy density } \\
\left(\mathbf{J} / \mathbf{m m}^{\mathbf{2}}\right)\end{array}$ \\
\hline $\mathbf{1}$ & 10 & 50 & 2000 & 2.2689 \\
\hline $\mathbf{2}$ & 30 & 50 & 2000 & 6.8067 \\
\hline $\mathbf{3}$ & 50 & 50 & 2000 & 11.345 \\
\hline $\mathbf{4}$ & 30 & 10 & 2000 & 34.034 \\
\hline $\mathbf{5}$ & 30 & 90 & 2000 & 3.78 \\
\hline $\mathbf{6}$ & 30 & 50 & 1000 & 13.61 \\
\hline $\mathbf{7}$ & 30 & 50 & 3000 & 4.54 \\
\hline
\end{tabular}

\subsection{Experimental details}

The purpose of this study was to find the optimal UNSM conditions that most improve a D2 surface. Surface roughness and hardness were selected as response values to analyze changes in surface characteristics before and after UNSM treatment. To measure the roughness of the UNSM treated surface, a contact-type surface roughness meter (Mitutoyo, SJ-410) were used. For each specimen, the roughness was measured ten times, and the average was adopted as a response value.

The hardness before and after UNSM treatment was measured using a micro-Vickers hardness tester from Mitutoyo (Hv-112), and indentation was performed for ten seconds using a load of $0.1 \mathrm{kgf}$. In addition, the hardness in a cross section was measured to examine the hardness inside the material after UNSM treatment (Fig. 3). Each specimen was cut, mounted, and then polished to \#2000 grit using silicon carbide ( $\mathrm{SiC}$ ) sandpaper. Finally, it was polished using 1 and $3 \mu \mathrm{m}$ diamond suspensions. Upon completion of all pretreatments, the hardness was measured at $20 \mu \mathrm{m}$ intervals in the depth direction from the point $20 \mu \mathrm{m}$ away from the top surface subjected to UNSM treatment. In this instance, five measurements were performed at each depth, and the average values were used as representative values.

An etching solution $\left(\mathrm{HNO}_{3}: 79.36 \mathrm{~mL}\right.$ and distilled water: $\left.20.64 \mathrm{~mL}\right)$ was used at an applied voltage and current of $2 \mathrm{~V}$ and $2 \mathrm{~A}$, respectively. The microstructure of the etched surface was examined using a field emission scanning electron microscope (FE-SEM, MIRA3, TESCAN). Additionally, EBSD analyses were performed to determine the phases and phase fraction. For the specimens treated with UNSM, the residual stress was measured. A Stresstech XSTRESS 3000 was utilized for measurement, and the $\sin 2 \Psi$ method that measures the stress from the strain of the lattice spacing was employed. If 
stress exists on the metal surface, the lattice spacing varies, changing the position of the X-ray diffraction peak. The residual stress can be measured by obtaining the lattice spacing according to the X-ray diffraction angle $(\sin 2 \Psi)$ [31]. The surface residual stress was analyzed with a $2 \mathrm{~mm}$ diameter collimator on a $70 \mathrm{~mm}$ arc using $\mathrm{Cu}-\mathrm{Ka}$ radiation.
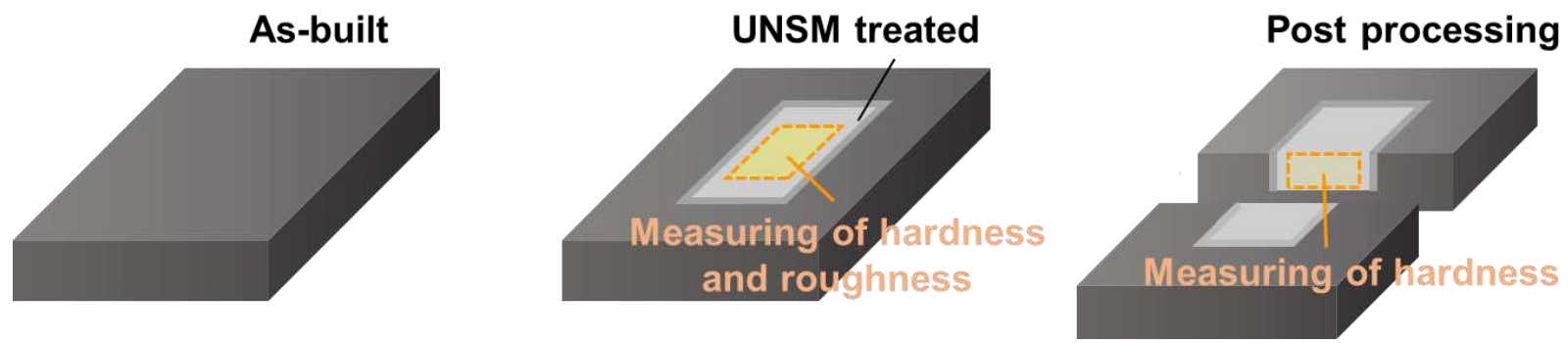

Fig. 3 Schematic diagram of UNSM treatment on base metal and preparation for analysis

\section{Results \& Discussion}

\subsection{Changes in roughness}

Fig. 4a. presents photographs of the specimens that were heat-treated at different tempering temperatures and then subjected to UNSM treatment under the conditions listed in Table 3. Surface changes caused by different conditions can be observed. Fig. 4b. shows the surface of the heat-treated D2 after the application of UNSM in more detail. Gloss is observed because micro-dimples were formed as the UNSM ball tip that vibrated 1.8 million times per minute struck the metal surface [22].

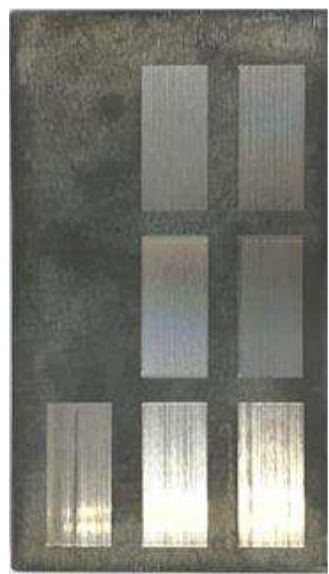

$\mathrm{D} 2-\mathrm{H} 40$

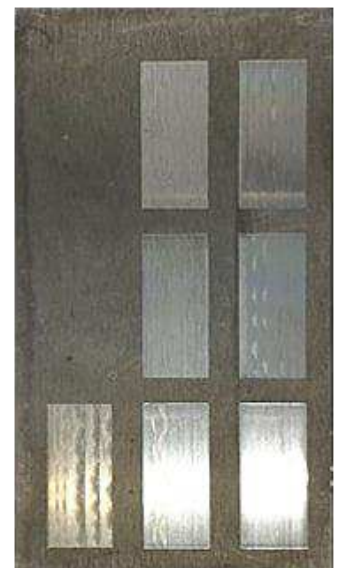

$\mathrm{D} 2-\mathrm{H} 45$

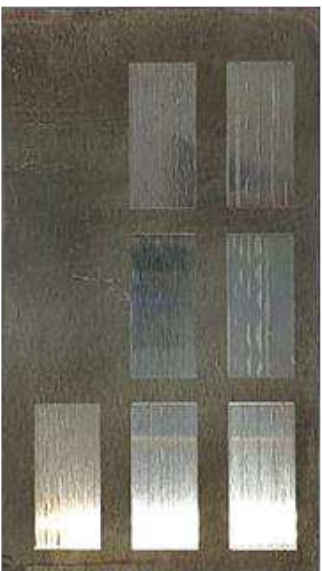

D2-H50

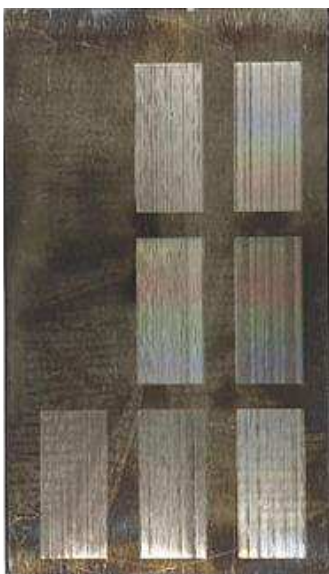

D2-H55

(a) 


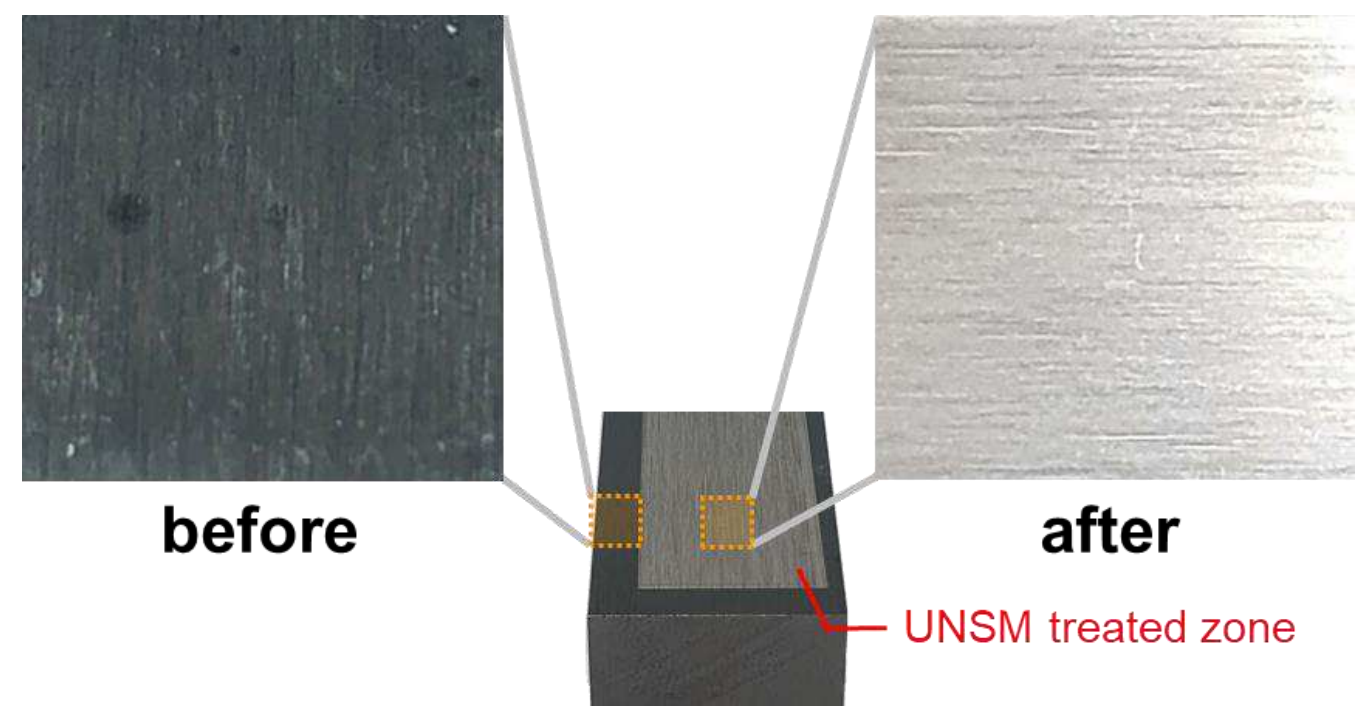

(b)

Fig. 4 (a) Photographs of UNSM-treated specimens, and (b) surface change before and after UNSM treatment

This study aimed to determine the UNSM process conditions suitable for surface improvement of the D2 base metal, which was heat-treated to have hardness values of $40,45,50$, and $55 \mathrm{HRc}$ (designated as D2-H40, D2-H45, D2-H50, and D2-H55, respectively). The average surface roughness Ra before UNSM treatment was $0.7 \mu \mathrm{m}$. The surface roughness values of all the UNSM-treated specimens decreased, regardless of the hardness and treatment conditions. Therefore, the roughness improvement rate $\Phi$ between before and after UNSM treatment was calculated as follows:

$$
\Phi(\%)=\frac{\Delta R a}{R a_{\text {initial }}} \times 100
$$

$\Delta R a$ represents the change in surface roughness between before and after UNSM treatment and is divided by the roughness value $\left(R a_{\text {initial }}\right)$ before treatment. The result is expressed as a percentage.

To compare the surface characteristics under different UNSM process conditions, Fig. 5. depicts the roughness and improvement rate between before and after treatment. Fig. 5a. shows the roughness results obtained when the feed rate was increased from 1,000 to 2,000 and $3,000 \mathrm{~mm} / \mathrm{min}$, while the load and inter-pass interval were fixed at $30 \mathrm{~N}$ and $50 \mu \mathrm{m}$, respectively. Under all conditions, the roughness is lower after treatment. In addition, the roughness after treatment increases with increasing feed rate for D2-H50 but shows no relationship to the feed rate for D2-H40, D2-H45, and D2-H55. This 
finding indicates that the feed rate does not significantly influence the roughness improvement.
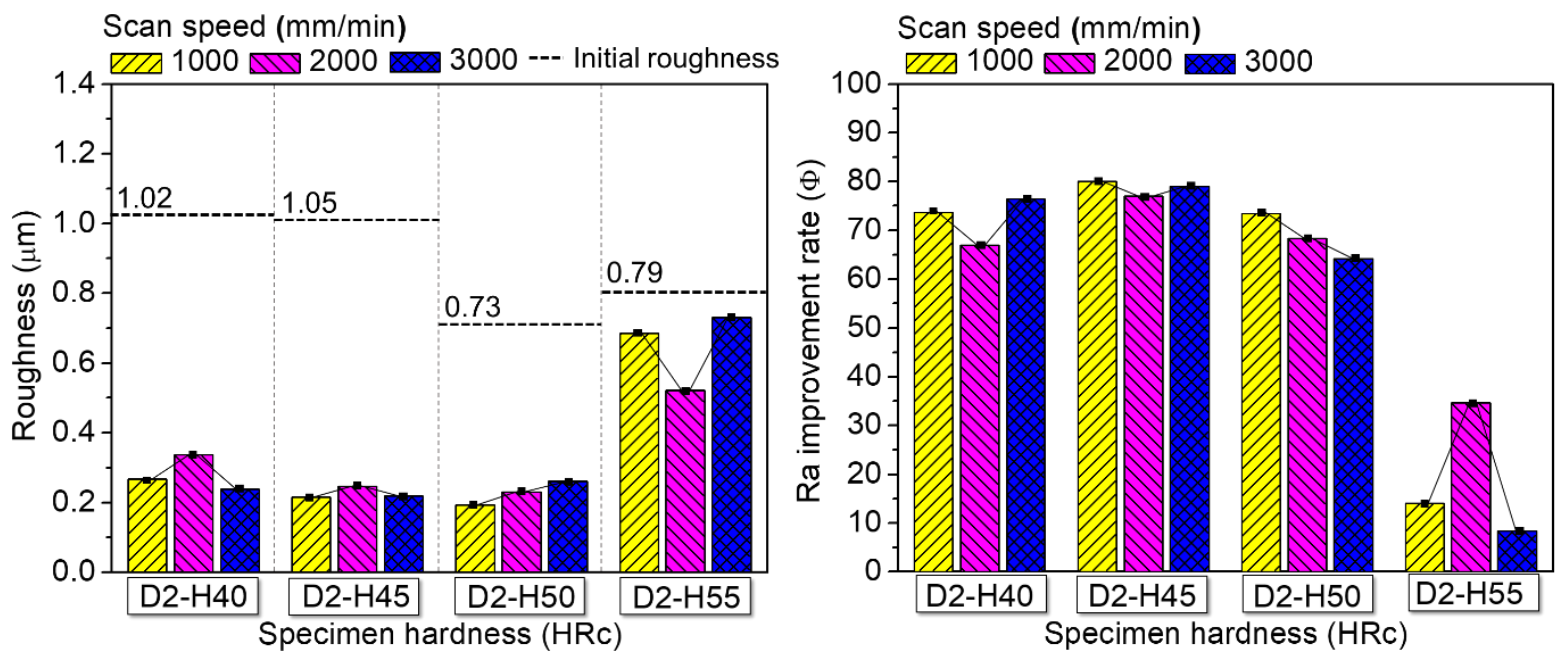

(a)
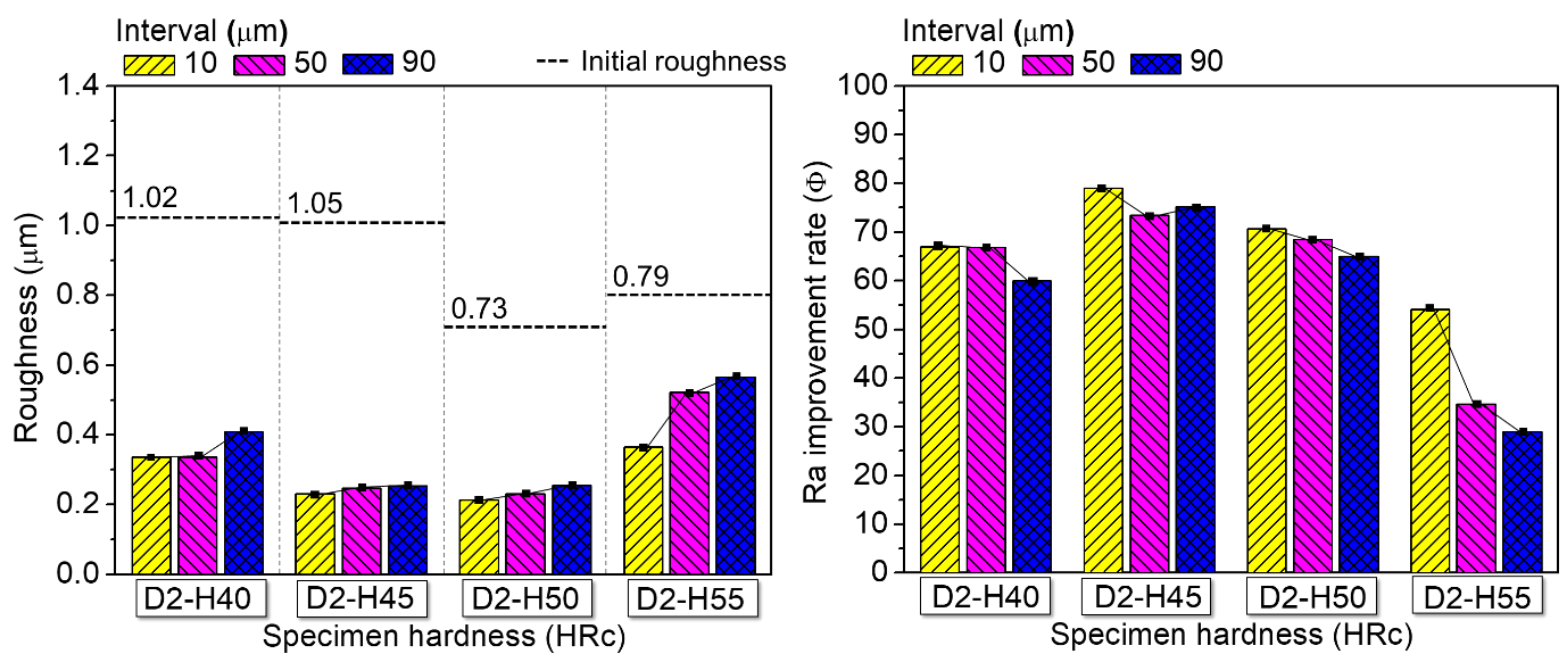

(b)
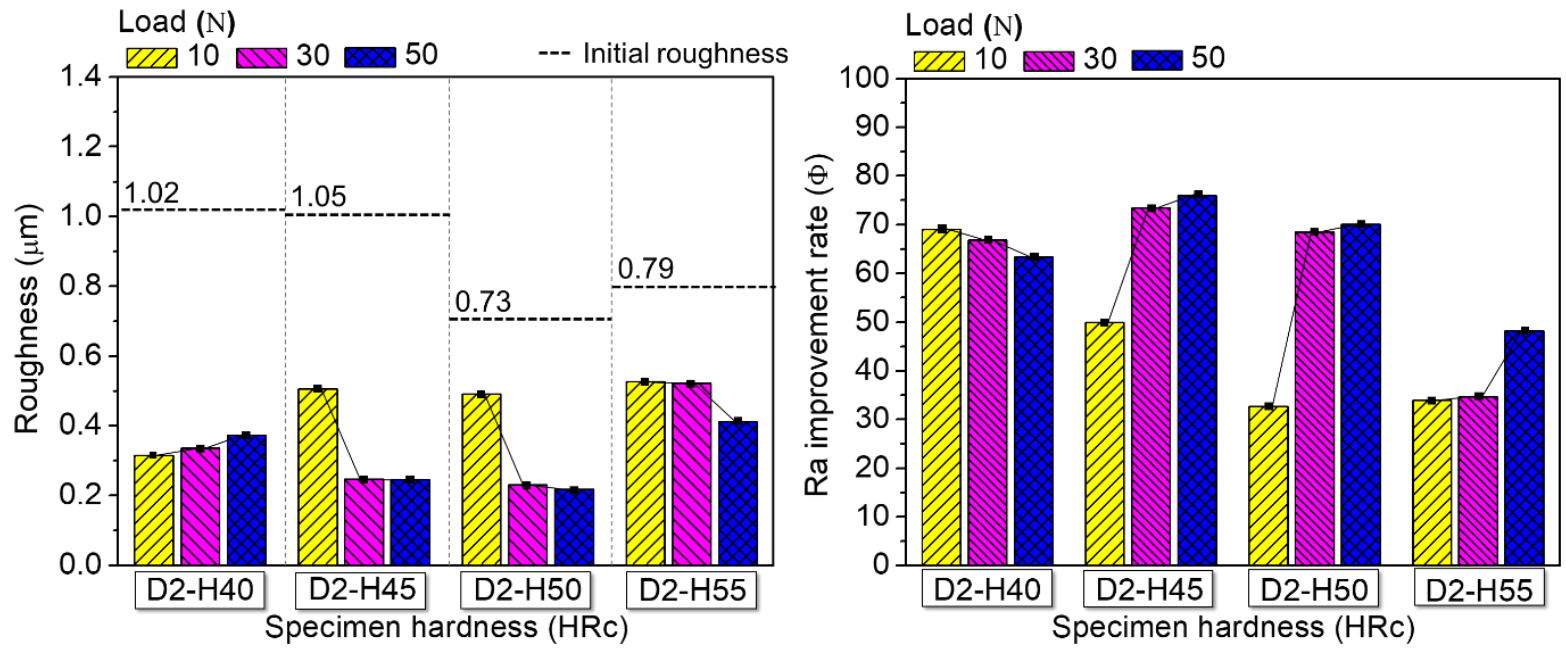
(c)

Fig. 5 Comparisons of the surface roughness (Ra) and improvement rate $(\Phi)$ among the specimens with different hardness values according to the UNSM process conditions of (a) feed rate, (b) interpass interval, and (c) load

The inter-pass interval was increased from 10 to 50 and $90 \mu \mathrm{m}$ while the load and feed rate were fixed at $30 \mathrm{~N}$ and $2,000 \mathrm{~mm} / \mathrm{min}$, respectively. Fig. 5b. presents the results. Regardless of the initial hardness, the roughness decreases, and the roughness improvement rate increases as the interval decreases. The greatest improvement rate is observed with an inter-pass interval of $10 \mu \mathrm{m}$ applied to D2-H45. Fig. 5c. shows the roughness results obtained when the load was varied while the inter-pass interval and feed rate were fixed at $50 \mu \mathrm{m}$ and $2,000 \mathrm{~mm} / \mathrm{min}$, respectively. For D2-H45, D2-H50, and D2-H55 with relatively high initial hardness, the roughness decreases and the roughness improvement rate increases as the static load increases. A smooth surface can be obtained under high static loads owing to the increase in the effect of peening. In the case of $\mathrm{D} 2-\mathrm{H} 40$, however, the roughness improvement rate decreases as the static load increases. Meanwhile, the roughness improvement rate of D2-H55 is significantly lower than those of the other specimens. However, with the highest applied load $(50 \mathrm{~N})$, the surface roughness is the lowest, and the improvement is the highest for D2-55. From these results, it can be concluded that it is necessary to apply a load higher than an appropriate level for the surface of a material with high hardness to exhibit a significant change in surface roughness.

\subsection{Surface topography}

Fig. 6 . shows the scanning electron microscope (SEM) images at $\times 500$ magnification for the surfaces treated at different inter-pass intervals. The set inter-pass interval of the UNSM is consistent with the interval between the formed tracks. When the interval is $90 \mu \mathrm{m}$, a relatively rough surface is evident, regardless of the initial hardness. However, as the interval decreases, a smoother surface is observed, because the number of impacts per unit area increases as the number of overlapping passes increases. Such overlapping passes deliver higher energy density to the metal surface. They are expected to affect the microstructure, mechanical characteristics, and surface characteristics significantly.

For detailed observation of the surface characteristics according to the initial hardness and UNSM conditions, the treated surface was analyzed. Fig. 7. presents the surface images of D2-H40 and D2H55 subjected to static loads of 10, 30, and 50 N. As shown in Fig. 7a, D2-H40 exhibits micro-valleys 
with crests and troughs formed by the passing ball tip under all load conditions. The micro-valleys become clearer as the static load increases. For detailed observation of the micro-valleys, they were magnified more $(\times 1000)$, revealing a relatively smooth surface under a $10 \mathrm{~N}$ load because the difference between the crests and troughs is not large. For the surfaces under loads of 30 and $50 \mathrm{~N}$, however, a rough surface is observed. In particular, with a $50 \mathrm{~N}$ applied load, irregular damage is evident owing to the high load, because the static load applied to the base metal with a low initial hardness exceeds the critical range. An excessive load increases the friction between the ball tip and material. It appears that such an increase in friction causes excessive plastic deformation [30] and decreases the roughness improvement rate. On the other hand, with low loads applied to D2-H55, as shown in Fig. 7b, regular patterns are not observed on the surface. However, with high applied loads, regular micro-valleys are evident, significantly improving the surface roughness. As described, the static load within the critical load range is helpful for improving the roughness owing to the effect of peening. A static load that exceeds the critical level, however, reduces the roughness improvement. 

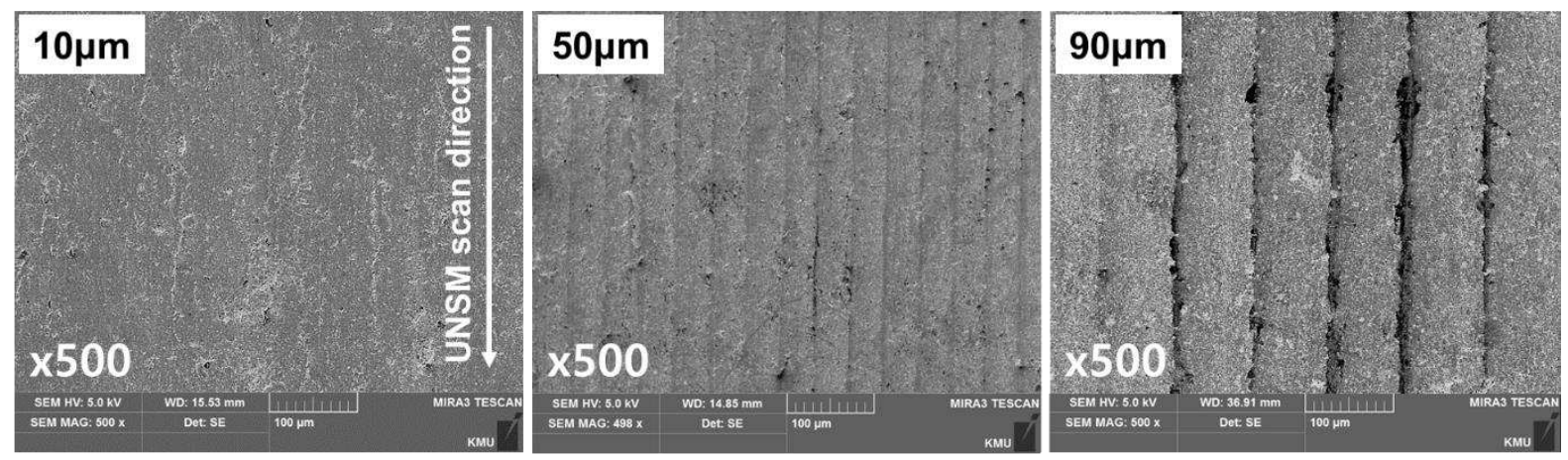

(a)
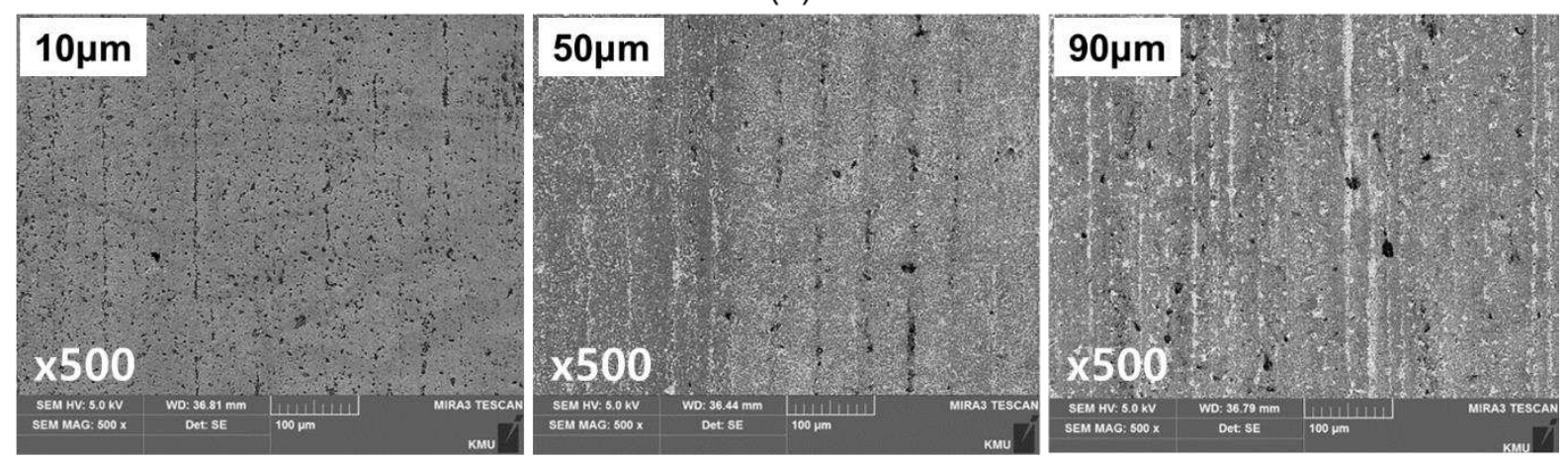

(b)
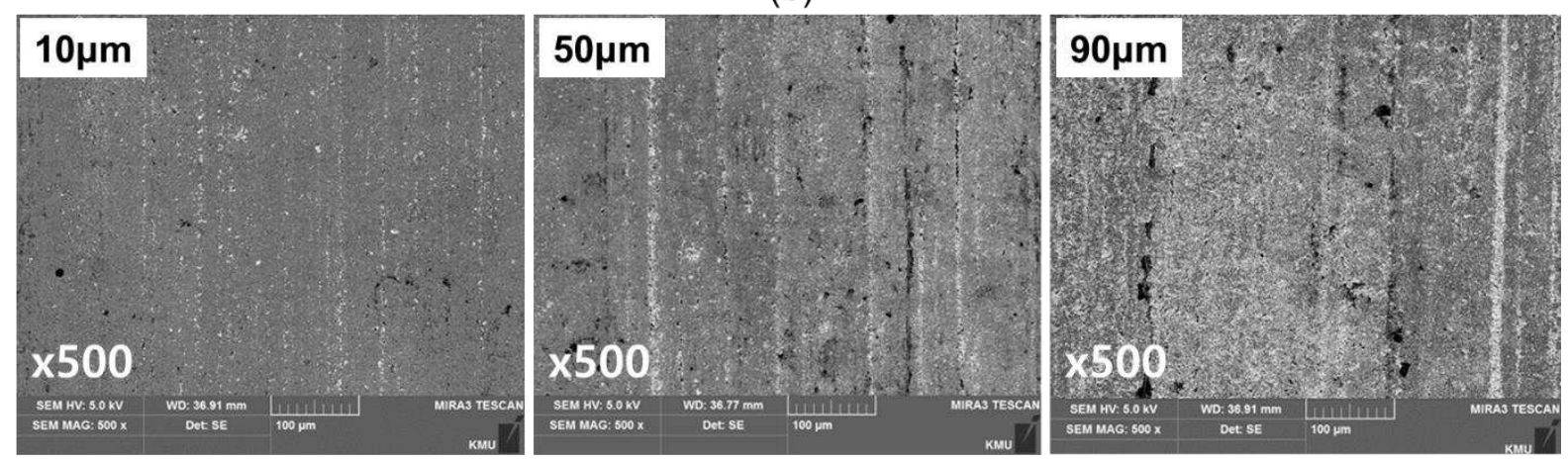

(c)
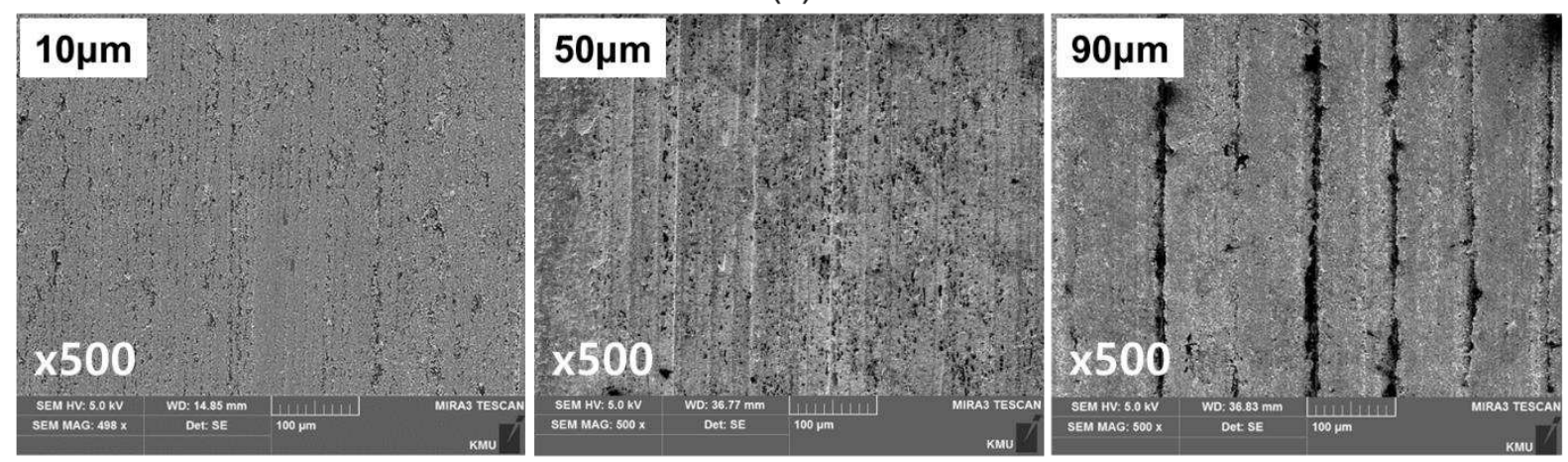

(d)

Fig. 6 Surface SEM images of specimens with different hardness values according to the inter-pass interval of UNSM: (a) D2-H40, (b) D2-H45, (c) D2-H50, and (d) D2-H55 

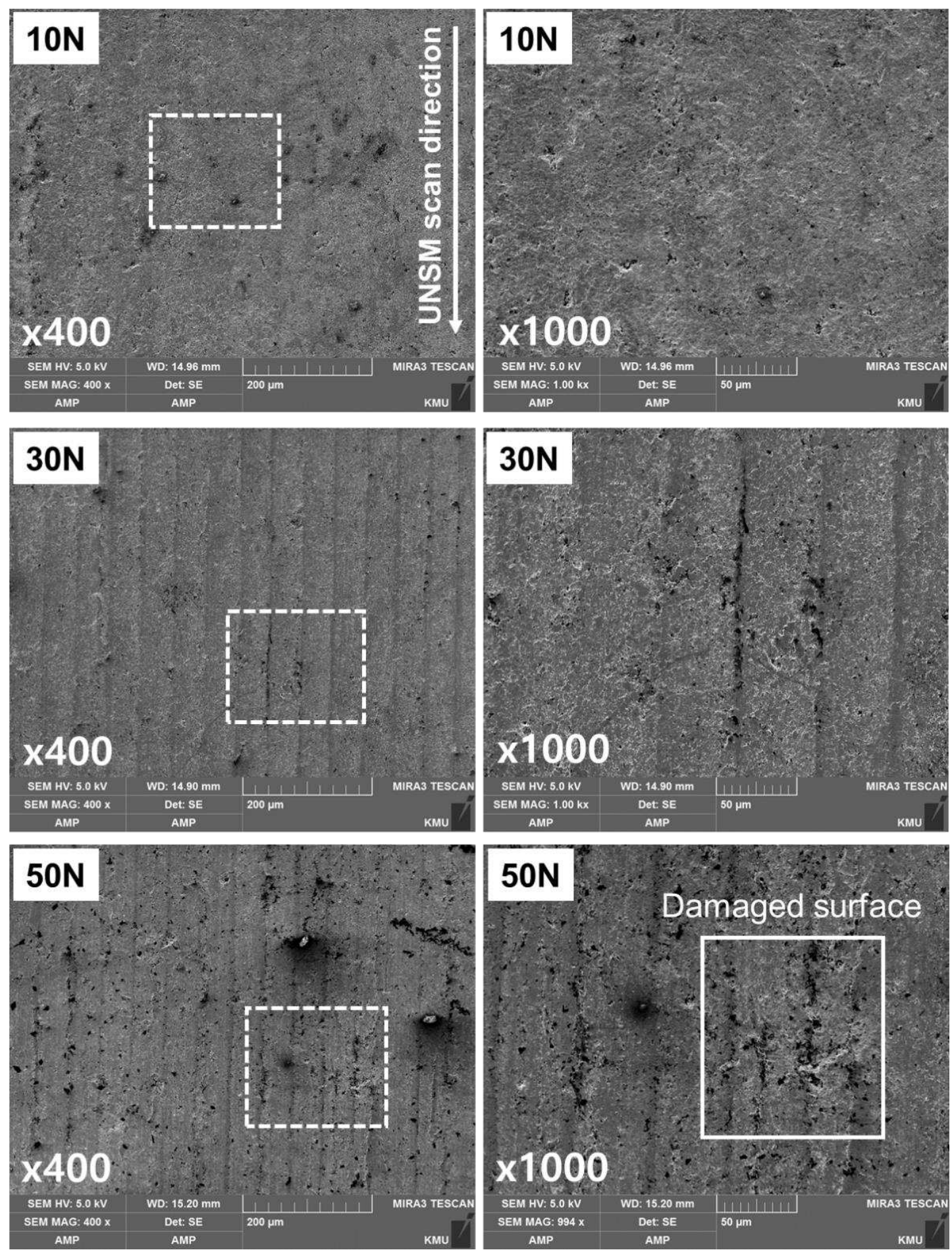

(a) 

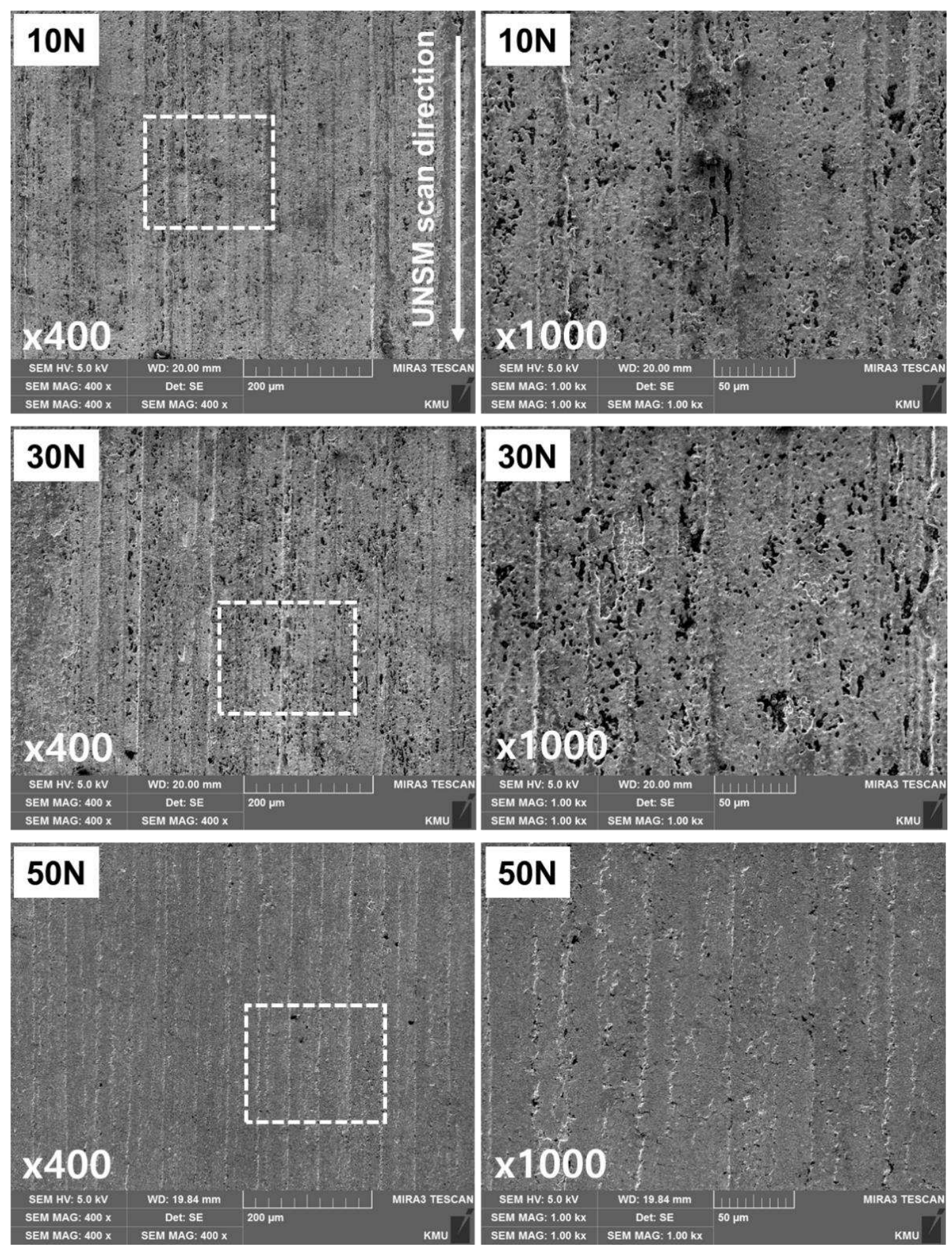

(b)

Fig. 7 Surface images according to the static load; (a) D2-H40, and (b) D2-H45

As described above, the application of the same load $(50 \mathrm{~N})$ resulted in different changes in $\mathrm{D} 2-\mathrm{H} 40$ and D2-H55. To observe the micro-valleys caused by UNSM treatment, the specimens were cut in a direction perpendicular to the UNSM treatment passes, as shown in Fig. 8. Fig. 8a. presents the results 
of applying a static load of $50 \mathrm{~N}$ to $\mathrm{D} 2-\mathrm{H} 40$. Cracks are observed in the surface zones, marked with white dotted lines. Wave-shaped patterns appear owing to the plastic deformation of the material under an excessive load, and cracks are observed under the waves. It is estimated that the roughness improvement rate is reduced when a load of $50 \mathrm{~N}$ is applied to $\mathrm{D} 2-\mathrm{H} 40$ owing to the generation of these wave patterns and cracks. In addition, these features may act as starting points for corrosion, thereby reducing the corrosion resistance [30]. In the case of D2-H55, however, the top surface was leveled through the ball tip, unlike $\mathrm{D} 2-\mathrm{H} 40$, as shown in Fig. $8 \mathrm{~b}$. When magnified at $\times 7,000$ magnification, uniformly compressed microstructures are observed in the moving direction of the UNSM ball tip. Consequently, the surface roughness could be decreased by applying an appropriate static load according to the initial hardness of the base metal. For D2-H45, D2-H50, and D2-H55, $50 \mathrm{~N}$ decreased the surface roughness as an appropriate load. For D2-H40, however, the application of $50 \mathrm{~N}$ damaged the surface and increased the roughness. These results indicate that the roughness improvement increases as the inter-pass interval decreases regardless of the initial hardness of the base metal but that the static load effectively improves the roughness only when it lies within the critical range. An increase in the static load (within the critical range) may increase the dislocation density by leveling the surface, thereby improving the corrosion resistance [30].

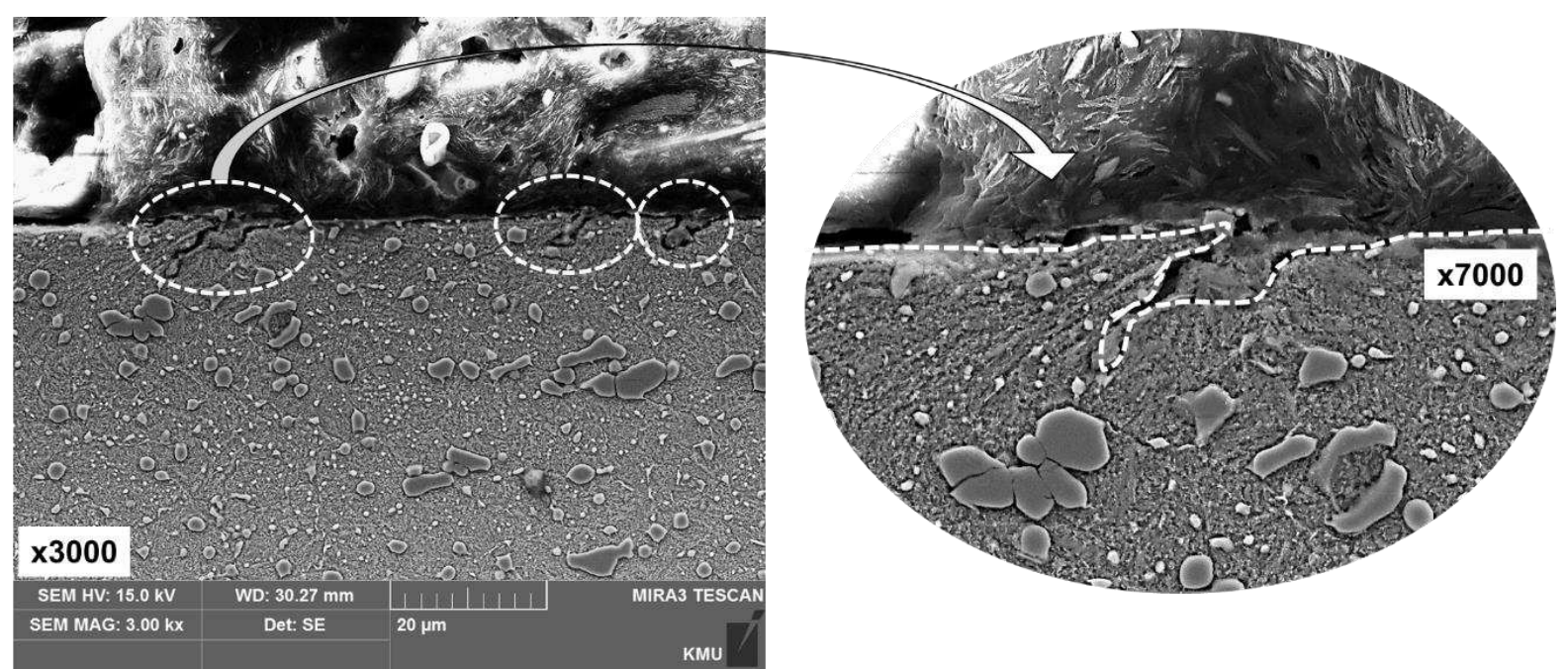

(a) 


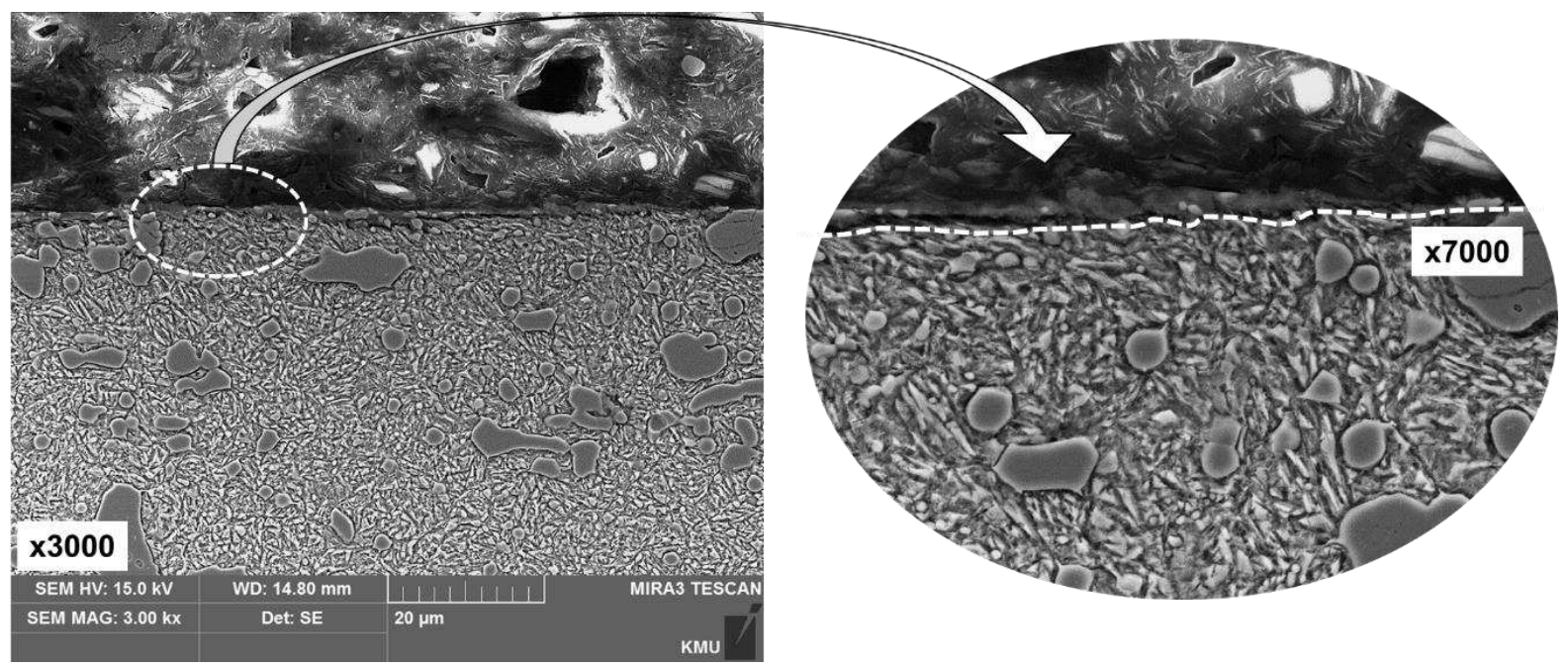

(b)

Fig. 8 SEM images of the cross sections near the base metal surfaces under $50 \mathrm{~N}$ : (a) D2-H40, and (b) D2-H55

\subsection{Hardness}

\subsubsection{Surface hardness}

To examine the changes in surface hardness after UNSM treatment, the surface hardness of each treated specimen was measured. The micro-Vickers hardness values of D2-H40, D2-H45, D2-H50, and D2-H55 before UNSM treatment were 420, 460, 530, and $620 \mathrm{Hv}$, respectively. As with the surface roughness change between before and after UNSM treatment described above, the surface hardness increased for all specimens after UNSM treatment, regardless of the process conditions. The hardness improvement rate $\Phi^{\prime}$ was calculated in the same manner as the surface roughness improvement rate, as shown in Eq. (1). Fig. 9. presents the results. Fig. 9a. depicts the hardness results according to the feed rate. As with the surface roughness change, there is no relationship between the hardness and feed rate. Fig. 9b. shows the hardness results according to the inter-pass interval. For all specimens, the highest hardness is observed when the interval is $10 \mu \mathrm{m}$, because the areas impacted by the ball tip overlap with each other as the interval decreases, thereby increasing the compression of the surface microstructure and grain refinement. Regarding the hardness change due to the load (Fig. 9c), the hardness increases, and the hardness improvement rate also increases almost linearly as the load increases. An increase in the load applied per unit area causes larger plastic deformation, which decreases the grain size and hinders dislocation sliding. Therefore, an increase in the load increases the hardness owing to the strain hardening of the material. The Hall-Petch relation shown in Eq. (2) 
indicates that the yield strength of a material $\mathrm{H}_{v}$ increases as the average grain diameter $\mathrm{d}$ decreases. Here, $\sigma_{\mathrm{i}}$ is the friction stress that hinders intragranular dislocation motion, and $\mathrm{k}_{\mathrm{y}}$ is a constant representing the relative hardening contribution of the grain boundary. In addition, the above equation can be represented by Eq. (3), which indicates that the hardness $\mathrm{Hv}$ increases as the grain size $d$ decreases. Here, $H_{0}$ and $k_{H}$ are constants based on hardness [32].

$$
\begin{aligned}
& \sigma_{0}=\sigma_{\mathrm{i}}+\mathrm{k}_{\mathrm{y}} \mathrm{d}^{-\frac{1}{2}} \\
& \mathrm{Hv}=H_{0}+k_{H} d^{-\frac{1}{2}}
\end{aligned}
$$

Based on this principle, the hardness increases as the grain size decreases owing to UNSM treatment. In addition, as the amount of energy applied per unit area increases, the hardness increases owing to the generation of a larger compressive residual stress. Therefore, as the inter-pass interval decreases and the load increases, the hardness improvement rate increases because the conditions are more favorable for grain refinement and the formation of compressive residual stress. The next section presents quantitative comparisons of grain refinement and compressive residual stress.
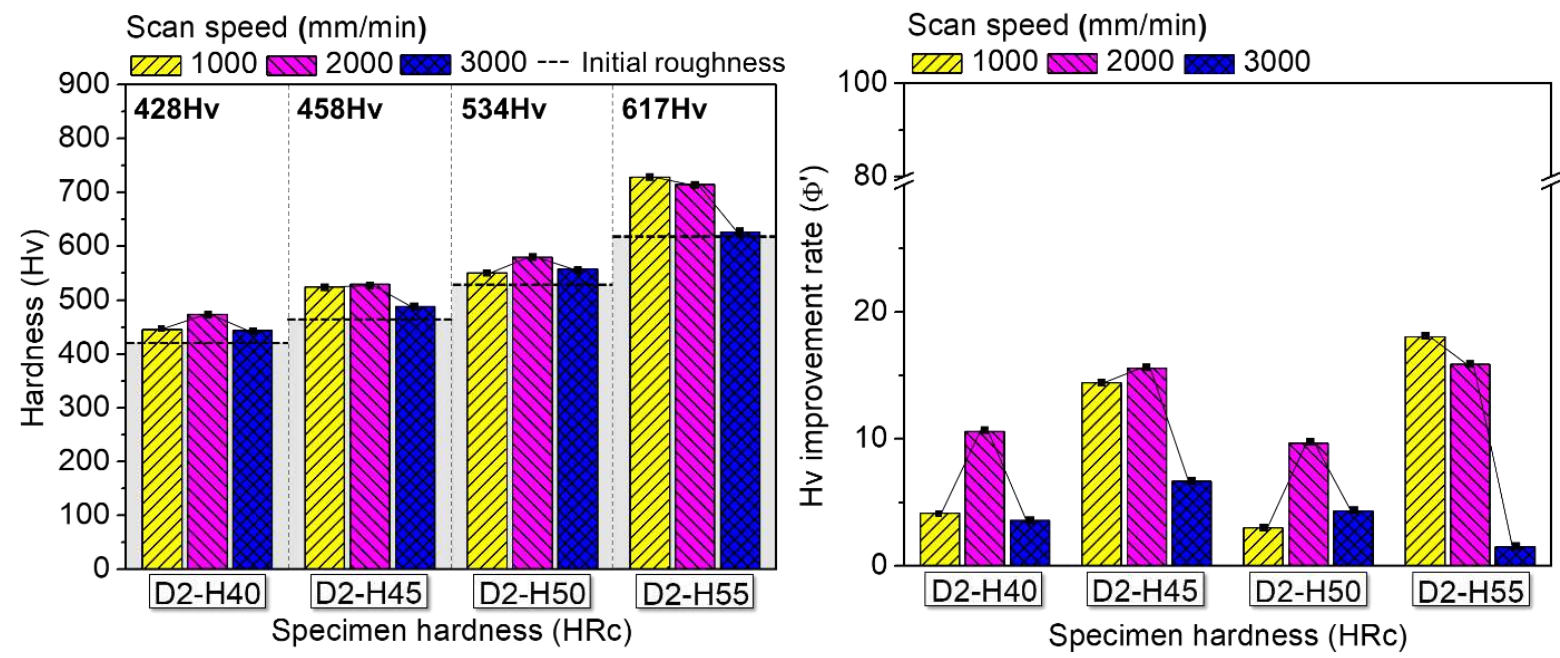

(a) 

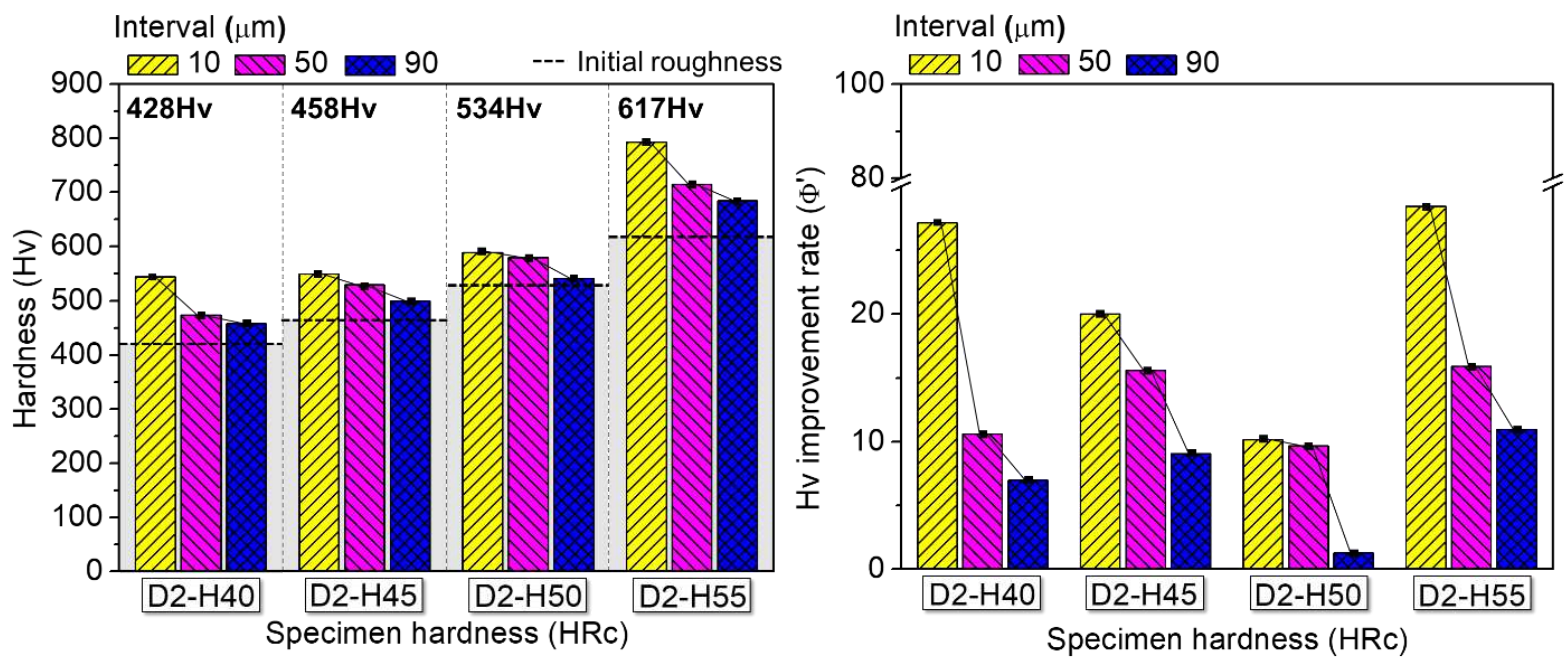

(b)
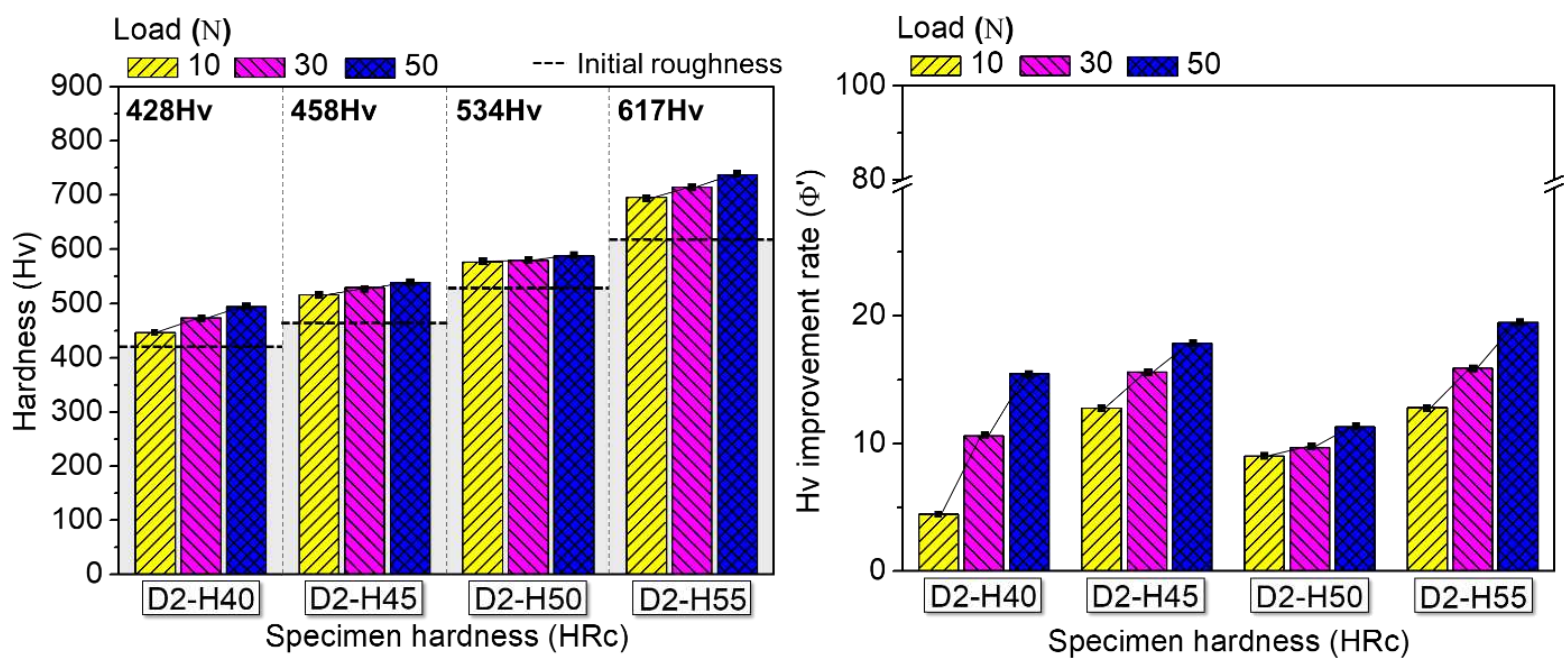

(c)

Fig. 9 Comparisons of the surface hardness and hardness improvement rate $\left(\Phi^{\prime}\right)$ according to the UNSM process conditions of (a) feed rate, (b) inter-pass interval, and (c) load

\subsubsection{Hardness in cross-section}

An increase in load also affects the depth of the surface upon which the impact of the UNSM is applied. Khan reported that a high static load in UNSM increased the hardening depth by generating smaller grains and deeper nanocrystalline layers [33]. The cross-sectional hardness values of the specimens under the highest static load of $50 \mathrm{~N}$ were measured. Fig. 10. shows the hardness values of D2-H40, D2-H45, D2-H50, and D2-H55 in the depth direction. As with the surface hardness, the hardness near the surface is increased by UNSM, and a significant increase in hardness is observed mainly in the upper part. The hardness decreases as the depth increases, and it converges to the same 
value as the initial hardness of each base metal when a certain depth is reached. The depth affected by UNSM and hardness improvement differ depending on the base metal, as depicted in Fig. 11. First, the depth affected by UNSM ranges from 220 to $400 \mu \mathrm{m}$. D2-H40 exhibits the greatest UNSM-affected depth $(400 \mu \mathrm{m})$. For D2-H55, on the other hand, the hardness increase by UNSM is observed only at a depth of $220 \mu \mathrm{m}$. In other words, the UNSM-affected depth tends to decrease as the initial hardness of the base metal increases. For the material with low hardness, nanocrystallization is formed at a greater depth under the same load because plastic flow occurs more easily. On the other hand, D2-H40 exhibits the lowest hardness improvement rate of $6.1 \%$. D2-H55, which has the lowest UNSM-affected depth, exhibits the greatest hardness improvement rate of $8.7 \%$. UNSM is a technology that modifies microstructures by delivering impact energy using ultrasonic waves. Such impacts can be considered as micro-cold forging. They cause plastic and elastic deformation in the surface layer, leading to nanocrystalline structures and compressive residual stress. The nanocrystalline structures and residual stress were analyzed to investigate the behavior of the hardness improvement rate in the depth direction.
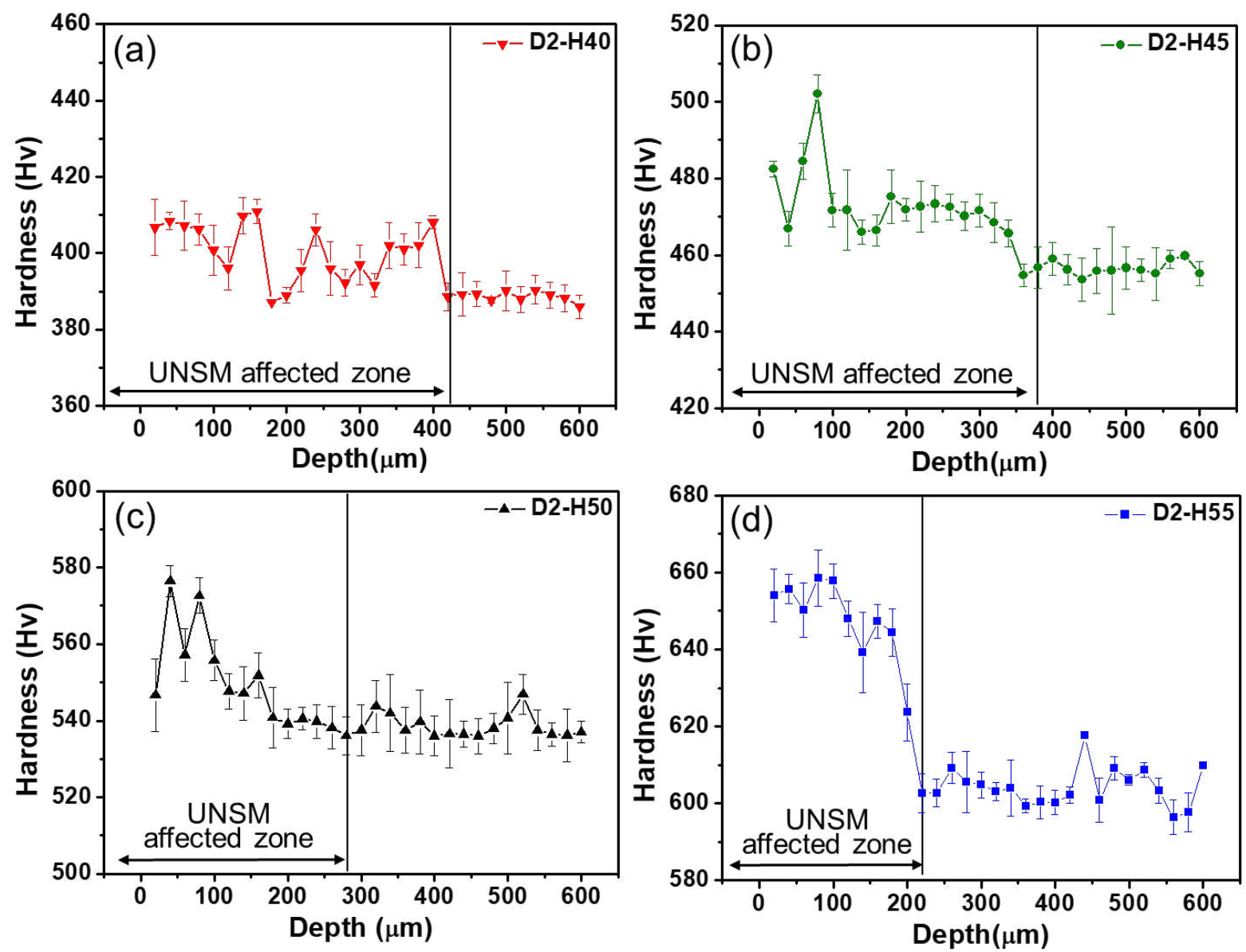

Fig. 10 Cross-sectional hardness distribution around the surface; (a) D2-H40, (b) D2-H45, (c) D2- 


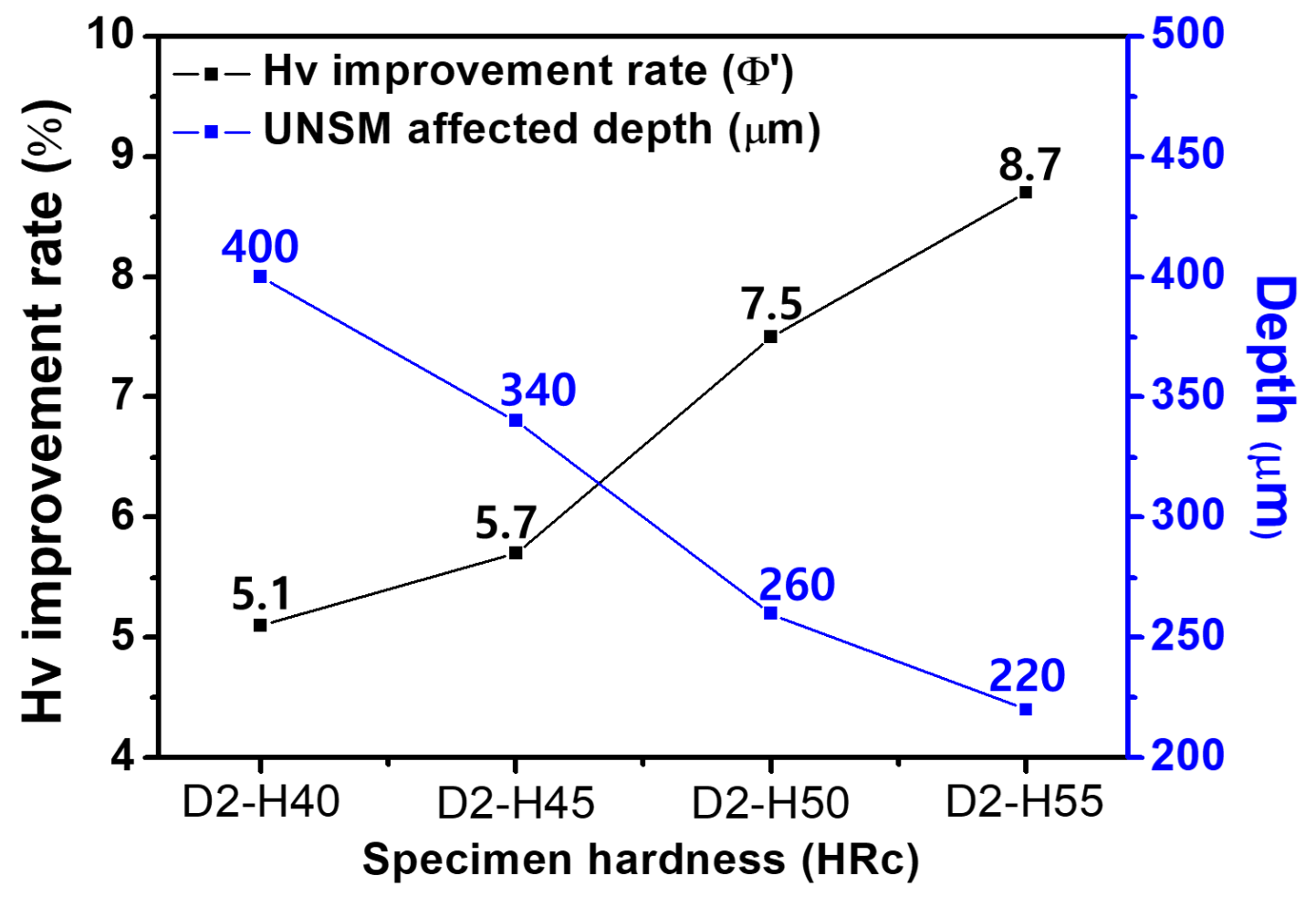

Fig. $11 \Phi^{\prime}$ and UNSM-affected depth according to initial base metal hardness

\subsection{Electron backscatter diffraction (EBSD) results and residual stress}

\subsubsection{Changes in grain size}

As can be seen from Hall-Petch (Eq. 2), a decrease in grain size indicates an increase in hardness. If nanocrystal grains are formed in deep areas, the thickness of the hardened layer increases. For D2$\mathrm{H} 40$, tempering was performed at a relatively high temperature. For D2-H55, however, tempering was performed at a low temperature. Thus, a high hardness was obtained owing to the fine microstructure, but the ductility decreased. To examine the microstructural refinement according to the heat treatment conditions of the base metal, the grain changes were observed using EBSD. Fig. 12. shows the phase diagrams of the specimens with different hardness values. Red represents martensite (or ferrite), blue corresponds to austenite, and the other colors indicate carbide. Regardless of the hardness of the base metal, most of the phases were transformed from the austenite phase to martensite due to quenching. The austenite phase either appears rarely or is not observed. Chromium carbides $\left(\mathrm{Cr}_{23} \mathrm{C}_{6}\right.$ and $\left.\mathrm{Cr}_{7} \mathrm{C}_{3}\right)$ are partially distributed in the structures and precipitated during quenching. 


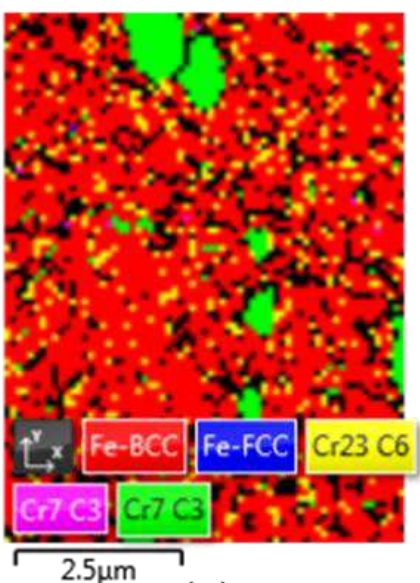

(a)

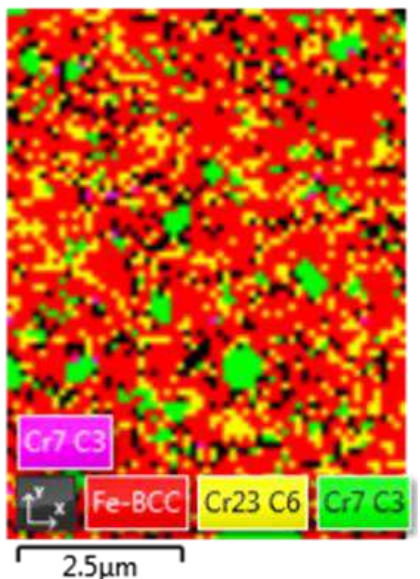

(c)

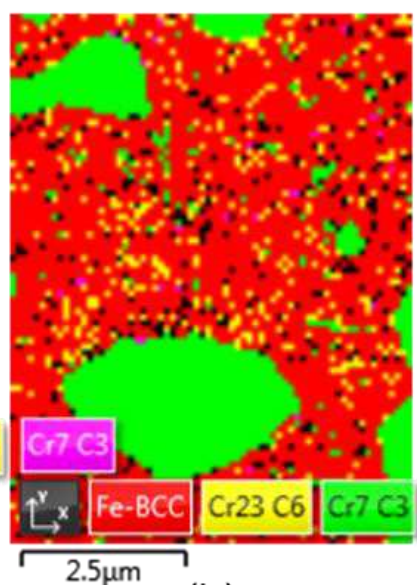

(b)

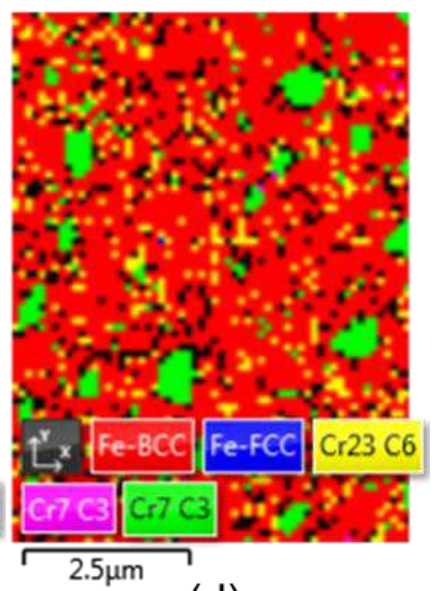

(d)

Fig. 12 Phase diagram maps of specimens (a) D2-H40, (b) D2-H45, (c) D2-H50, and (d) D2-H55

Fig. 13. compares the grain sizes of D2-H40 (Fig. 13a) and D2-H55 (Fig. 13b) before and after UNSM treatment. The average grain size of $\mathrm{D} 2-\mathrm{H} 55$ before the treatment is $0.51 \mu \mathrm{m}$, which is smaller than that of $\mathrm{D} 2-\mathrm{H} 40(0.65 \mu \mathrm{m})$. The average grain size of $\mathrm{D} 2-\mathrm{H} 40$ decreases by approximately $18 \%$, from 0.65 $\mu \mathrm{m}$ before treatment to $0.53 \mu \mathrm{m}$ after treatment. Meanwhile, the average grain size of D2-H55 decreases by approximately $29 \%$, from $0.51 \mu \mathrm{m}$ to $0.36 \mu \mathrm{m}$. As the grains in the upper part of D2-H55 are further refined, the hardness improvement rate is higher than that of D2-H40 (Fig. 10). D2-H55 exhibits limited plastic flow because it has finer grains and more grain boundaries than D2-H40. D2$\mathrm{H} 55$, however, has a relatively low energy absorption through deformation because of its low ductility. Consequently, D2-H55 exhibits a low UNSM-affected depth under the same load, as shown in Fig. 10, because it has a relatively limited plastic flow and low energy absorption.

Fig. 14. shows the microstructural changes of D2-H40 and D2-H55 under the same load. For D2- 
$\mathrm{H} 40$, the plastic flow was free because its ductility was relatively high, which caused a large hardening depth by dispersing the impact energy into the surrounding area. Because the repeated impact loads of UNSM could easily be dispersed to the surrounding area, the degree of refinement was lower than that of D2-H55. Meanwhile, for D2-H55, grain refinement occurs only in a limited area even under repeated impact energy because the plastic flow is limited owing to the fine grains. Therefore, for D2H40 (Fig. 14a), the plastic flow and energy transfer caused by UNSM treatment extend over wide ranges. In the case of D2-H55 (Fig. 14b), on the other hand, only the narrow portion of the upper part exhibits plastic deformation because the plastic flow is limited compared to that in the case of $\mathrm{D} 2-\mathrm{H} 40$, but higher nanocrystallization is evident due to the concentration of energy without transfer.

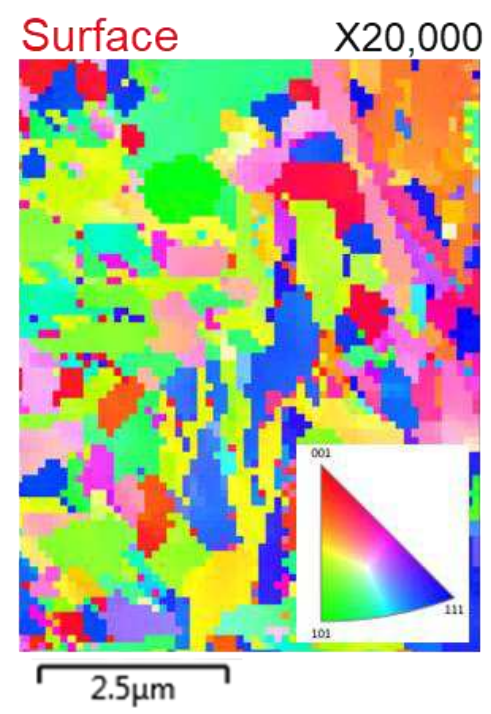

\section{Average:}

Average:

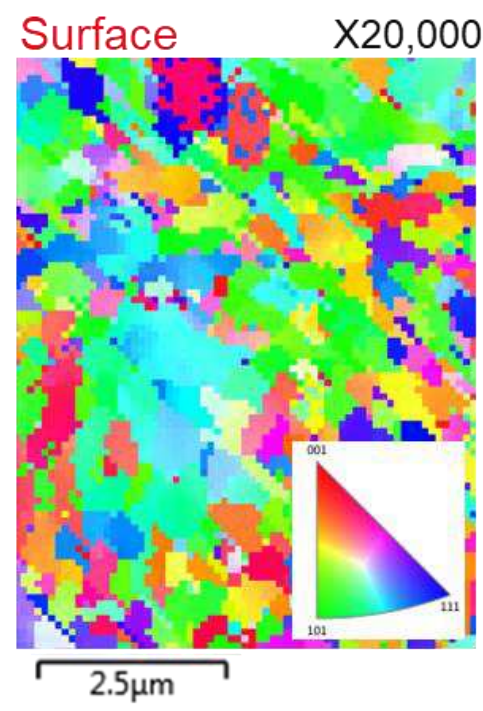

0.53 microns

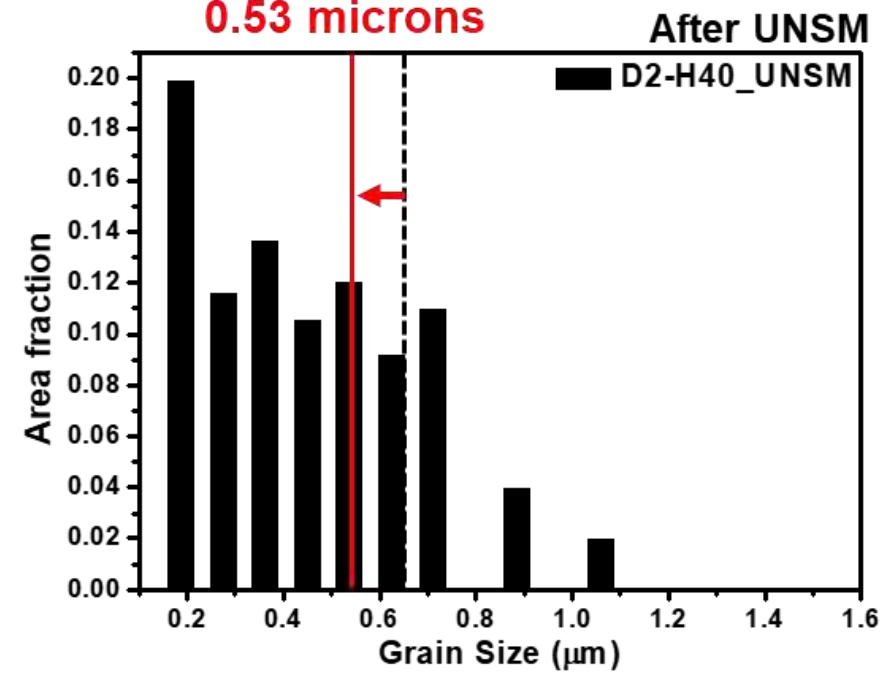


(a)

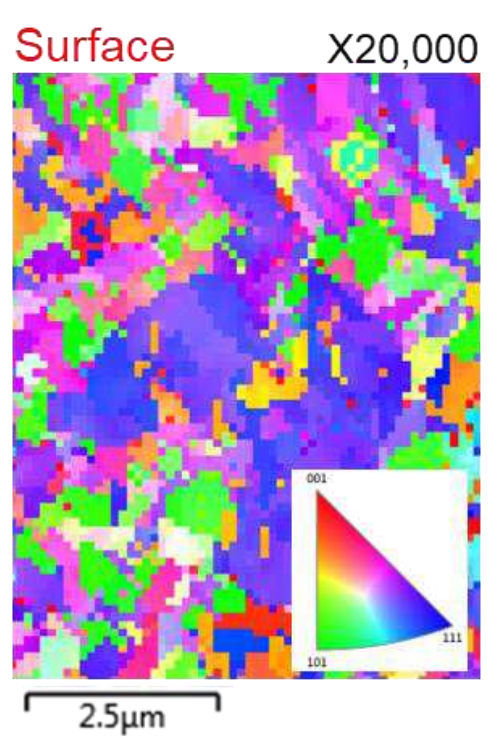

Average:

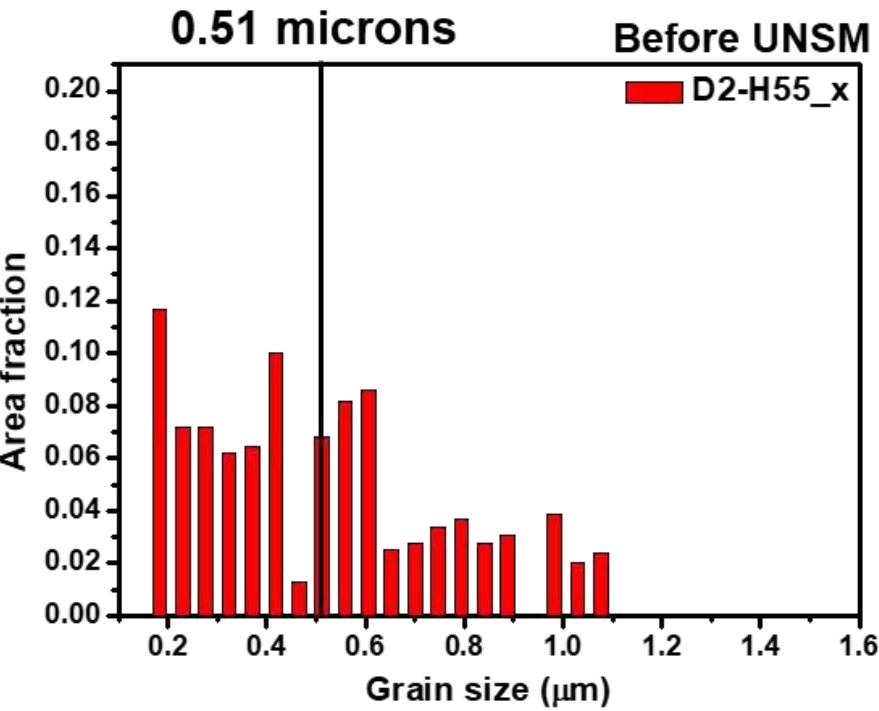

Average:

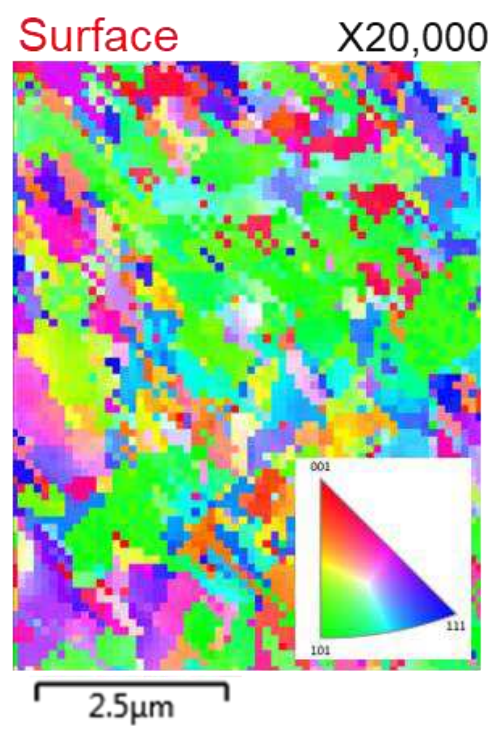

0.36 microns After UNSM

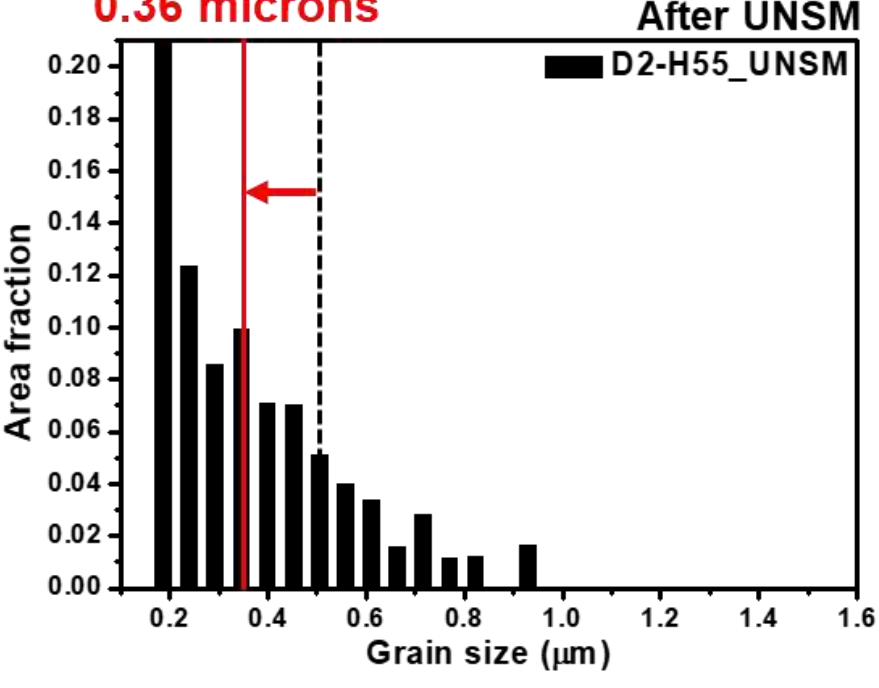

(b)

Fig. 13 Inverse pole figures and grain sizes of (a) D2-H40, and (b) D2-H55 before and after UNSM treatment 


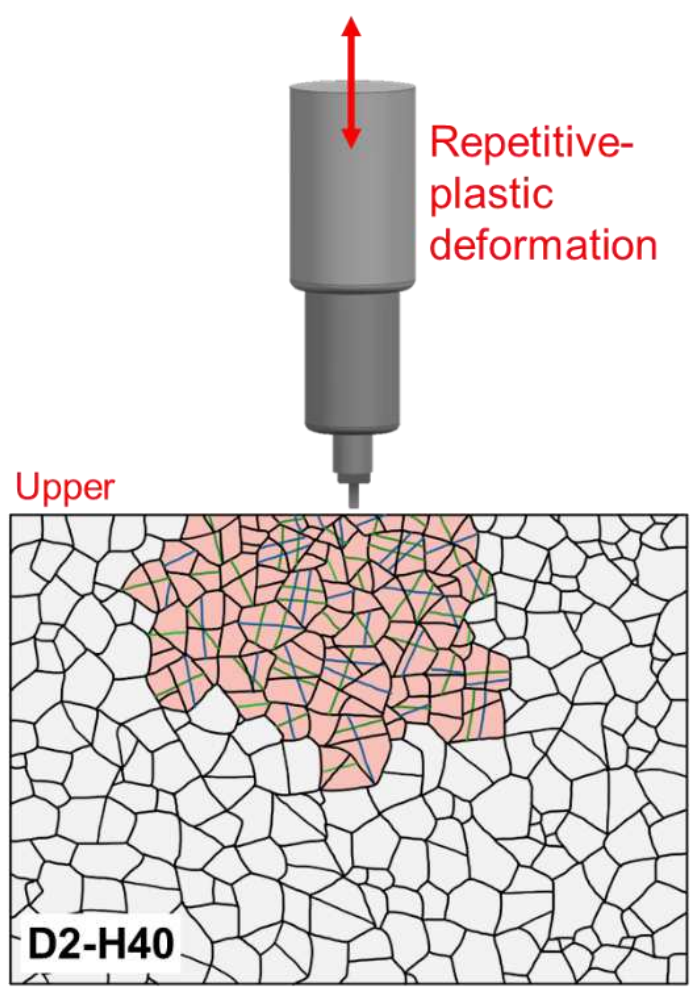

(a)

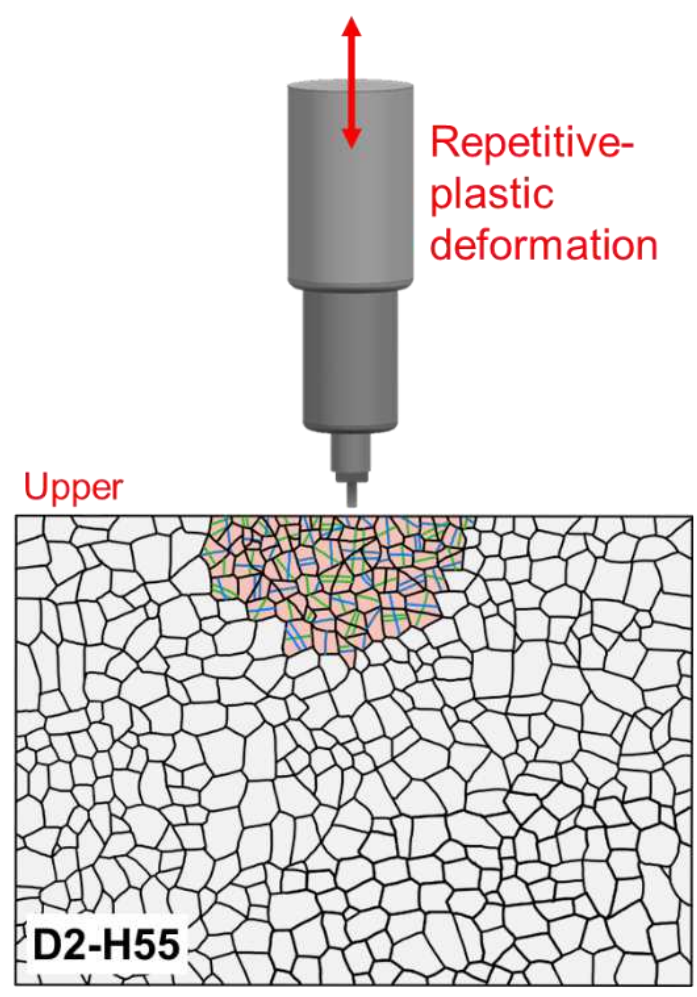

(b)

Fig. 14 Schematics of the microstructural changes induced by UNSM in (a) D2-H40, and (b) D2-H55

\subsubsection{Changes in residual stress}

If a material is subjected to repeated non-uniform plastic processing, heating, or cooling, residual stress is generated inside it. If such residual stress exists in the form of tensile stress, it may cause premature fracture of the material. UNSM forms a large compressive residual stress on the surface layer by delivering repeated compressive loads, improving the fatigue life of the material. To examine the formation of compressive residual stress according to the initial hardness of D2 under the same UNSM conditions, the surface residual stress was indirectly measured using the $\sin 2 \Psi$ method. The $\sin 2 \Psi$ method measures the stress through the strain of the lattice spacing caused by residual stress [31]. The residual stress was calculated using the following simple equation [34]:

$$
\sigma=\frac{E}{(1+v) \sin ^{2} \Psi}\left[\frac{d \psi-d_{0}}{d_{0}}\right]
$$

where, $\sigma$ is the residual stress, $d_{0}$ is the lattice spacing measured in the non-stress state, $d_{\psi}$ is the lattice spacing in the $\Psi$ direction changed by the stress, E is Young's modulus of the material, and $v$ is the Poisson's ratio.

Fig. 14. compares the compressive residual stresses formed on the surfaces of the specimens (D2- 
$\mathrm{H} 40$, D2-H45, D2-H50, and D2-H55). Firstly, before UNSM treatment, a low average tensile stress of 12.4 MPa is observed on the surface of each specimen, because stress relief occurred as the tempering was repeated three times after quenching. For each specimen, the compressive residual stress is at least 20 times higher after UNSM treatment regardless of the initial hardness of the base metal. Here, the same UNSM treatment conditions, that is, a load of $50 \mathrm{~N}$, an inter-pass interval of $20 \mu \mathrm{m}$, and a feed rate of 2,000 $\mathrm{mm} / \mathrm{min}$, were applied to each specimen. For D2-H40, a compressive residual stress of $679.2 \mathrm{MPa}$ is observed. As the initial hardness of the base metal increases, the compressive residual stress increases, and D2-H55 exhibits the highest compressive residual stress of 1,130.6 MPa. Under the same UNSM conditions, the hardness improvement rate also increases as the initial hardness of the base metal increases owing to the increase in the compressive residual stress formed on the surface. These results show that higher grain refinement and larger compressive residual stress are generated with increasing initial hardness. Therefore, the specimens with higher initial hardness values exhibit higher hardness improvement rates.

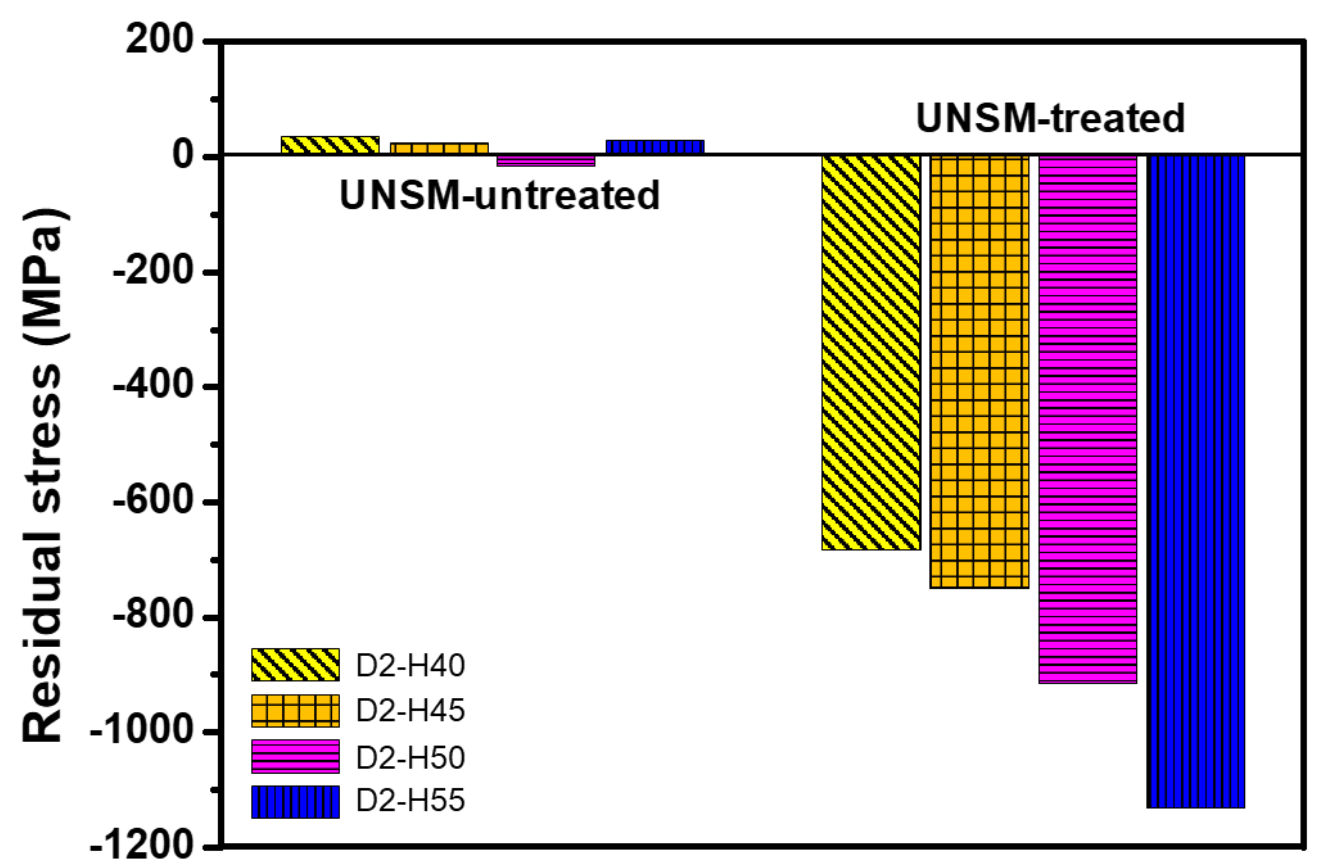

Fig. 15 Residual stress before and after UNSM treatment

\section{Conclusions}

In this study, the parameters (load, inter-pass interval, and feed rate) of UNSM were varied and applied to D2 base metals with different initial hardness values $(40,45,50$, and $55 \mathrm{HRc})$ through heat 
treatment at different temperatures. In addition, the changes in the surface and mechanical characteristics after UNSM were observed for each specimen. It was found that the surface roughness improvement rate increased as the inter-pass interval decreased regardless of the initial hardness of the base metal. In addition, an increase in the static load within the critical load range improved the roughness. For $\mathrm{D} 2-\mathrm{H} 40$, the specimen with an initial hardness of $40 \mathrm{HRc}$, however, the roughness improvement decreased under a load of $50 \mathrm{~N}$, which was excessive. Further, the surface hardness improvement increased as the load increased and the inter-pass interval decreased regardless of the initial hardness of the base metal. High loads and overlapping passes could deliver a higher energy density to the metal surface, which increased the hardness improvement because of the formation of fine crystal structures and large compressive residual stress. D2-H40, with the lowest initial hardness, exhibited the highest hardening depth of $400 \mu \mathrm{m}$ after the UNSM treatment. D2-H55, which had the highest initial hardness, exhibited the greatest hardness improvement rate of $8.7 \%$. For D2-H40, the plastic flow was free because its ductility was relatively high, which enabled grain refinement in deep areas because the impact energy of the UNSM was dispersed in the surrounding area. The hardness improvement rate of $\mathrm{D} 2-\mathrm{H} 40$, however, was lower than that of $\mathrm{D} 2-\mathrm{H} 55$ because the degree of grain refinement was small as the impact energy was dispersed. In the case of D2-H55, grain refinement occurred only in a narrow area because the plastic flow was limited. The hardness improvement could have been greater owing to the grain refinement in a limited area. These results were confirmed by grain size measurements through EBSD. After UNSM treatment, the grain size decreased by approximately $18 \%$ for $\mathrm{D} 2-\mathrm{H} 40$ and $29 \%$ for D2-H55. In addition, when the residual stress was measured, it was found that D2-H55 exhibited the largest compressive residual stress of $-1,130.6 \mathrm{MPa}$ after UNSM treatment under the same load.

The results of this study are expected to be used as basic data for setting the UNSM process conditions for the surface hardening of D2. However, the tendencies of the surface roughness and hardness according to the UNSM feed rate were not clearly observed in this study. It appears that the influence of the feed rate was not significant because the treated area of the ball tip was small. Therefore, in the future, the effects of the feed rate on the surface and mechanical characteristics will be observed by increasing the UNSM treatment area. In addition, the changes in the fatigue characteristics due to increasing compressive residual stress will be evaluated under the same conditions for D2-H40, D2$\mathrm{H} 45$, D2-H50, and D2-H55. 


\section{Acknowledgment}

This work was supported by the Korea Institute for Advancement of Technology (KIAT) through the European International R\&D Collaboration (grant number G02P03040000701). Additional support through the National Research Foundation of Korea (NRF) under grant number 2021R1A2C101197311 from the Ministry of Science and ICT is gratefully acknowledged.

Ethical Approval : Not applicable

Consent to Participate: Not applicable

Consent to Publish: Not applicable

Authors Contributions: Seung-Young Cho; Data curation, Formal analysis, and Writing - original draft, Do-Sik Shim; Writing - review \& editing, Supervision

Funding: Korea Institute for Advancement of Technology: G02P03040000701, National Research Foundation of Korea: 2021R1A2C101197311.

Competing Interests: The authors declare no conflict of interest.

Availability of data and materials: Data sharing is not applicable to this article.

\section{References}

1. Cho IS, Lee CS, Choi CH, Lee HG, Lee MG, Jeon Y (2017) Effect of the ultrasonic nanocrystalline surface modification (UNSM) on bulk and 3D-printed AISI H13 tool steels. Metals 7:510. https://doi:10.3390/met7110510

2. Yang SK, Kang JB (2004) Synthesis of aluminum nitride whisker by carbothermal reaction 1. Effect of fluoride addition. J Kor Ceram Soc 41:118-124. https://doi.org/10.4191/kcers.2004.41.2.118

3. Wang J, Lin Y, Yan J, Zen D, Zhang Q, Huang R, Fan H (2012) Influence of time on the microstructure of AISI 321 austenitic stainless steel in salt bath nitriding. Surf Coat Technol 206:3399-3404. https://doi.org/10.1016/j.surfcoat.2012.01.063

4. Li GJ, Peng Q, Li C, Wang Y, Gao J, Chen SY, Wang J, Shen BL (2008) Effect of DC plasma nitriding temperature on microstructure and dry-sliding wear properties of $316 \mathrm{~L}$ stainless steel. Surf Coat Technol 202:2749-2754. https://doi.org/10.1016/j.surfcoat.2007.10.002

5. Kim YS, Park JR (1999) Plasma nitriding and plasma nitrocarburizing of metals and alloys. J Weld Join Soc 17:6-11

6. Jeong $\mathrm{KH}$, Lee IS (2008) The influence of Ar gas in the nitriding of low temperature plasma 
carburized AISI304L stainless steel. J Kor Inst Met Mater 46:125-130

7. Lee IS (2011) The influence of treatment condition during low temperature plasma carburizing of AISI304L stainless steel. J Kor Soc Ocean Eng 25:56-60. https://doi.org/10.5574/KSOE.2011.25.1.056

8. Yang BM, Park KC (1996) Characteristics of surface modification by thermal spraying. J KWS $14: 19-27$

9. Kim YS, Nam KW, Kim HS, Oh MS, Kim KS (1998) Mechanical properties of metal/ceramic FGM made by thermal spraying method. J Power Syst Eng 2:41-48

10. Song SH, Choi BH (2001) A study on the characteristics and the prediction of the fatigue strength of the induction surface hardened steel. J Kor Soc Precis Eng 18:122-130

11. Lee DS, Lee KJ, Kim TH, Cheong SK (2005) A study on the wear characteristic of automobile gear material by shot peening. Proc Spring/Autumn Conf Kor Soc Auto Eng 2034-2038

12. Kim JC, Cheong SK (2012) Microscopic analysis of effect of shot peening on corrosion fatigue behavior of aluminum alloy. J Kor Soc Mech Eng 11:1381-1389. https://doi.org/10.3795/KSMEA.2012.36.11.1381

13. Cheong SK, Lee SH, Chung SC (2001) Effect of the peening intensity by shot peening. J Kor Soc Mech Eng 10:1590-1596. https://doi.org/10.22634/KSME-A.2001.25.10.1590

14. Han MS, Hyun KY, Kim SJ (2013) Effects of shot peening time on microstructure and electrochemical characteristics for Cu alloy. J Kor Soc Mar Environ Saf 19:545-551. https://doi.org/10.7837/kosomes.2013.19.5.545

15. Wu J, Liu H, Wei P, Zhu C, Lin Q (2020) Effect of shot peening coverage on hardness, residual stress and surface morphology of carburized rollers. Surf Coat Technol 384:125273. https://doi.org/10.1016/i.surfcoat.2019.125273

16. Girish DV, Mayuram MM, Krishnamurthy S (1997) Influence of shot peening on the surface durability of thermomechanically treated En 24 steel spur gears. Tribol Int 30:865-870. https://doi.org/10.1016/S0301-679X(97)00073-X

17. Oguri K (2011) Fatigue life enhancement of aluminum alloy for aircraft by fine particle shot peening (FPSP). J Mater Process Technol 211:1395-1399. https://doi.org/10.1016/j.jmatprotec.2011.03.011

18. Kim JH, Lee WR, Kim TG, Cheong SK (2011) Micro-shockwave measurement and evaluation of laser shock peening. J Kor Soc Mech Eng 10:1041-1046

19. Kim JC, Kim JH, Jung SK (2009) Hardness variation of Ti-6Al-4V by laser peening process. Proc Autumn Conf Kor Soc Precis Eng 507-508

20. Yang SY, Choi SD, Jun JM, Gong BC (2010) Improving the residual stress characteristics of the metal surface by Nd: TAG laser shock peening. J Kor Soc Manuf Technol Eng 19:539-547

21. Kang H, Lee S (2019) Residual Compressive Stress Characteristic of AL6061-O using Electromagnetic Peening. SASE 2019 Spring Conf 5-6

22. Lee SC, Kim JH, Kim HD, Choi GS, Amanov A, Pyun YS (2015) Changes in mechanical properties of WC-Co by ultrasonic nanocrystal surface modification technique. J Kor Soc Tribol Lubr Eng 4:157-162. https://doi.org/10.9725/kstle.2015.31.4.157

23. Kheradmandfard M, Kashani-Bozorg SF, Kim CL, Hanzaki AZ, Pyoun YS, Kimc JH, Amanovc A, Kim DE (2017) Nanostructured $\beta$-type titanium alloy fabricated by ultrasonic nanocrystal surface modification, Ultrasonics Sonochem 698-706. 
http://dx.doi.org/10.1016/i.ultsonch.2017.03.061

24. Lim TW, Lee CS, Cho IS, Amanov A (2020) Better surface integrity and tribological properties of steel sintered by powder metallurgy. Materials 13:3172. https://doi.org/10.3390/ma13143172

25. Cao X, Xu X, Wang C, Pyoun Y, Wang Q (2017) Effect of ultrasonic surface impact on the fatigue behavior of Ti-6Al-4V subject to simulated body fluid. Metals 7:440. https://doi.org/10.3390/met7100440

26. Ma C, Dong Y, Ye C (2016) Improving surface finish of 3D-printed metals by ultrasonic nanocrystal surface modification. Proc CIRP 45:319-322. https://doi.org/10.1016/i.procir.2016.02.339

27. Amanov A, Kim JH, Pyun YS (2016) Microstructure and friction behavior of AISI 52100 and D2 steels subjected to ultrasonic nanocrystalline surface modification (UNSM) technique at a high temperature. Mater Sci Forum 879:164-168

28. Pyun YS, Kim HS, Son KG, Song GH, Kim MK, Kang JH, Choi BU, Park J, Cho IH, Kim CS, Park JH, Kinney J (2005) Development of D2 tool steel trimming knives with nanoscale microstructure. Proc Conf Mater Sci Technol

29. Kim MS, Shin GY, Park SH, Shim DS (2020) Optimization of ultrasonic nanocrystal surface modification (UNSM) for improving surface quality of direct energy deposited AISI 316L. J Mater Res Technol 9:102-122. https://doi.org/10.1016/j.jmrt.2020.10.092

30. Kim KT, Kim YS (2019) The effect of the static load in the UNSM process on the corrosion properties of alloy 600. Materials 12:3165. https://doi.org/10.3390/ma12193165

31. Wong SM (1978) Residual stress measurements on chromium films by $x$-ray diffraction using the sin2 b method. Thin Solid Films 53:65-71. https://doi.org/10.1016/0040-6090(78)90374-7

32. Ko YB, Lee JH, Park KC (2009) Microstructures of friction stir lap weld in A5052-H112 alloy. J KWJS 27:17-24. https://doi.org/10.5781/KWJS.2009.27.6.017

33. Khan MK, Liu YJ, Wang QY, Pyun YS, Kayumov R (2016) Effect of ultrasonic nanocrystal surface modification on the characteristics of AISI 310 stainless steel up to very high cycle fatigue. Fatigue Fract Eng Mater Struct 39:427-438. https://doi.org/10.1111/ffe.12367

34. Li Y, Lu Z, Li T, Li D, Lu J, Liaw PK, Zou Y (2020) Effects of surface severe plastic deformation on the mechanical behavior of 304 stainless steel. Metals 10:831. https://doi.org/10.3390/met10060831 
Figures

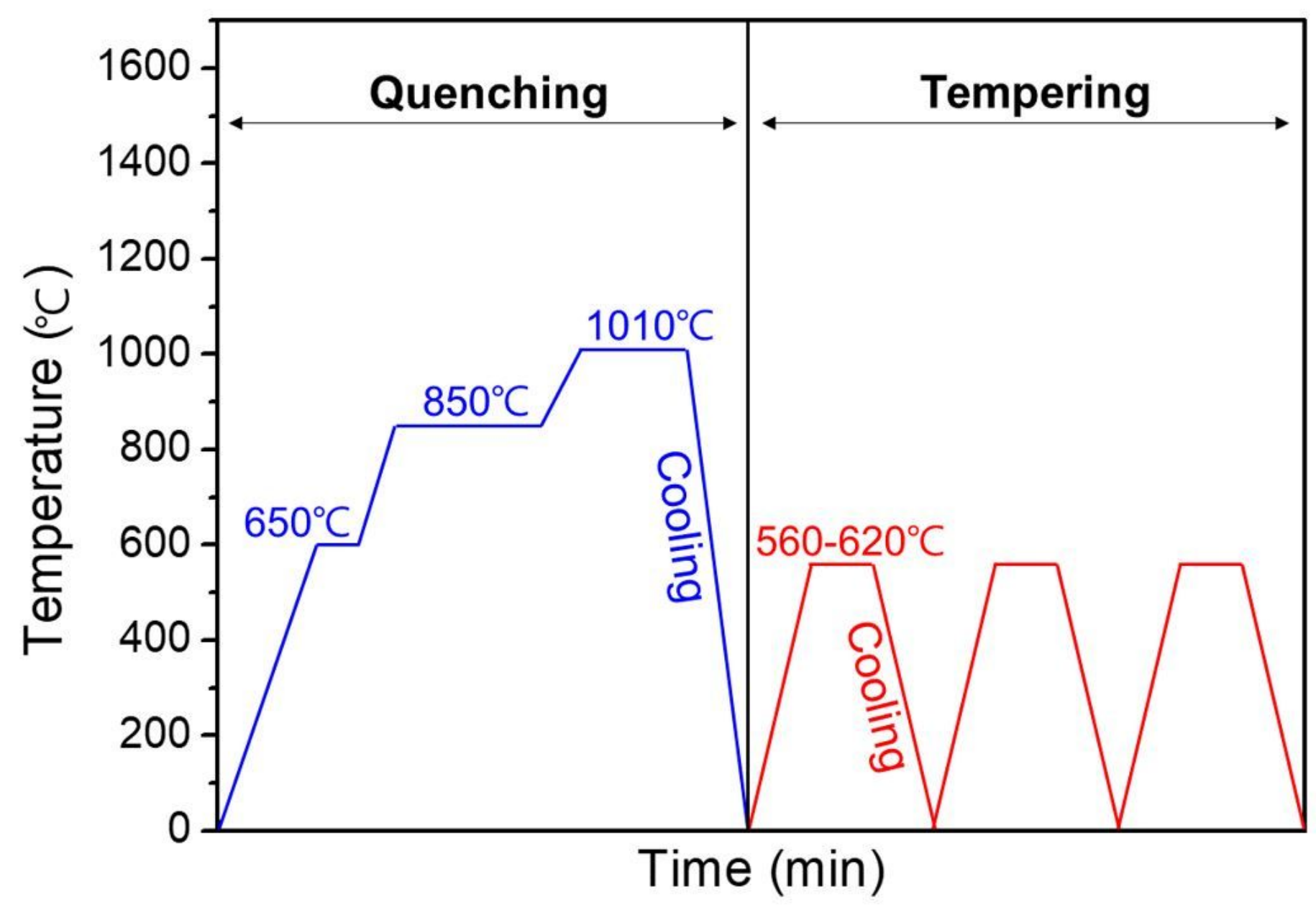

Figure 1

Schematic representation of heat-treatment process for $D 2$ 

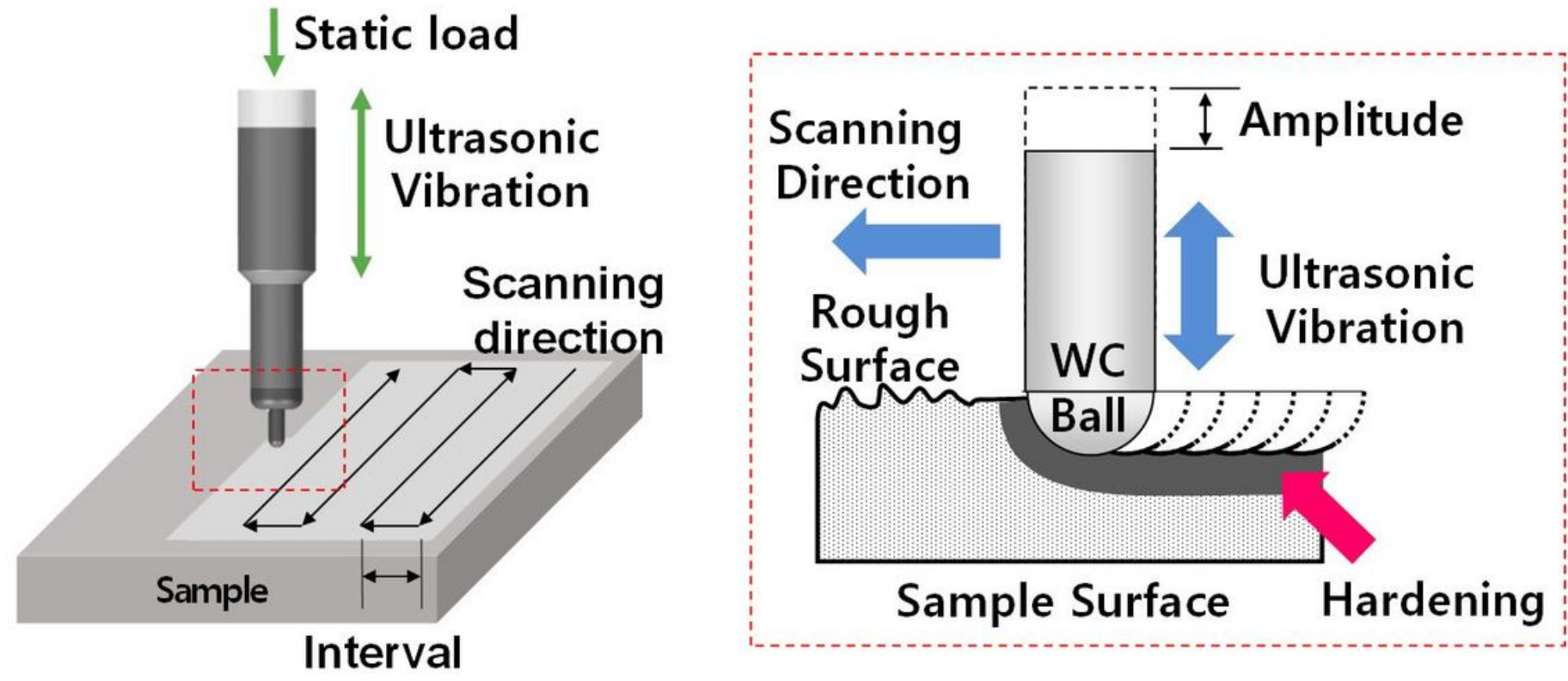

Figure 2

Schematics of the (a) UNSM experimental setup, and (b) UNSM principles
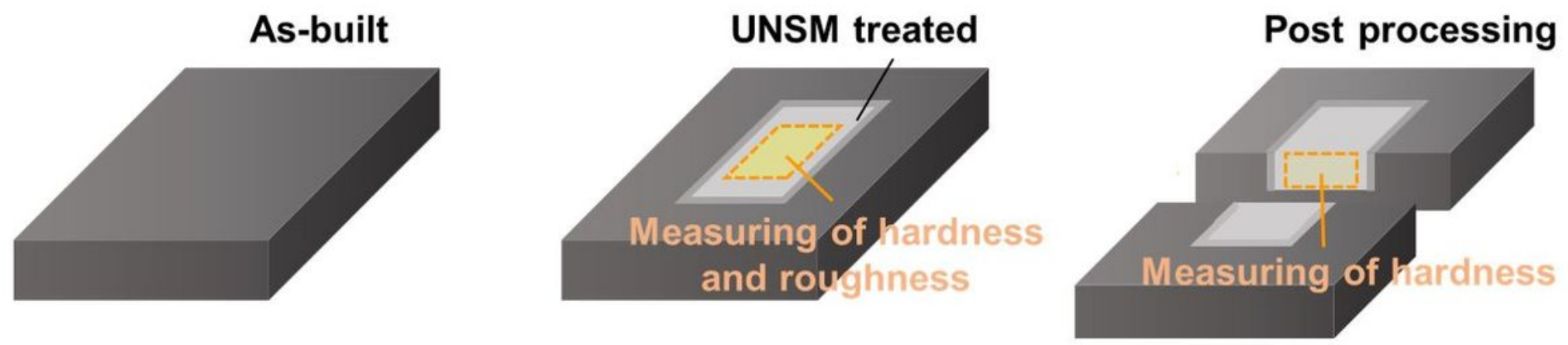

Figure 3

Schematic diagram of UNSM treatment on base metal and preparation for analysis 


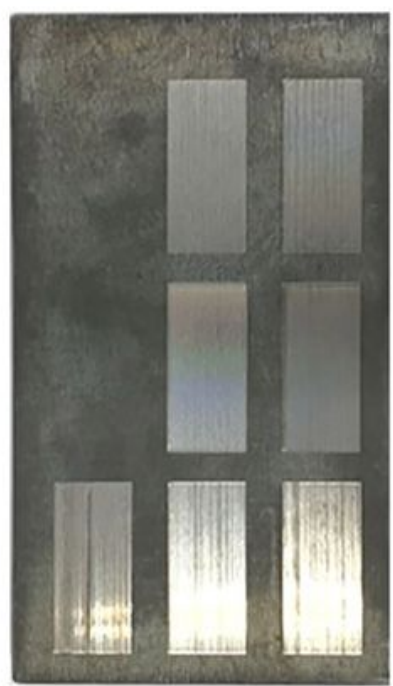

$\mathrm{D} 2-\mathrm{H} 40$

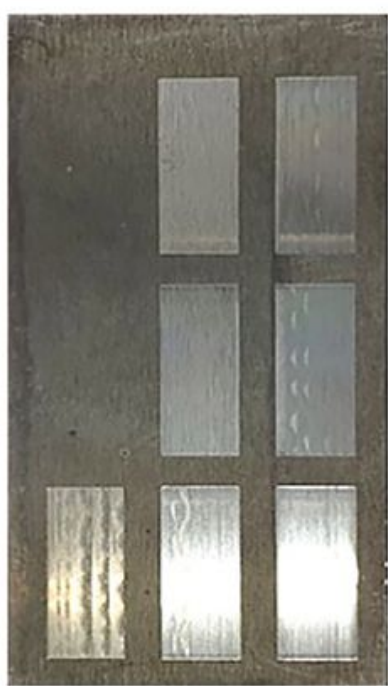

$\mathrm{D} 2-\mathrm{H} 45$

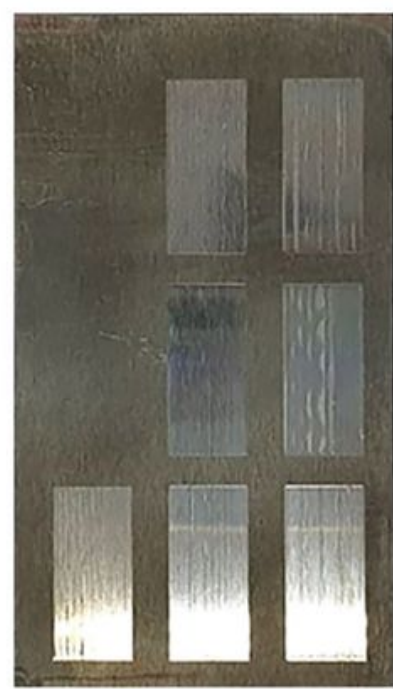

$\mathrm{D} 2-\mathrm{H} 50$

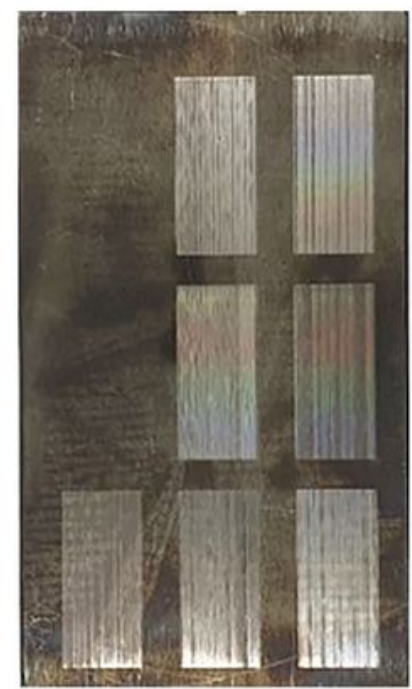

D2-H55

(a)

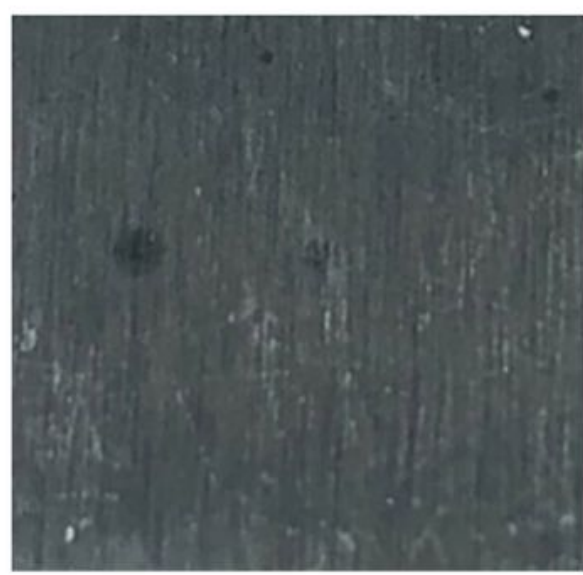
before

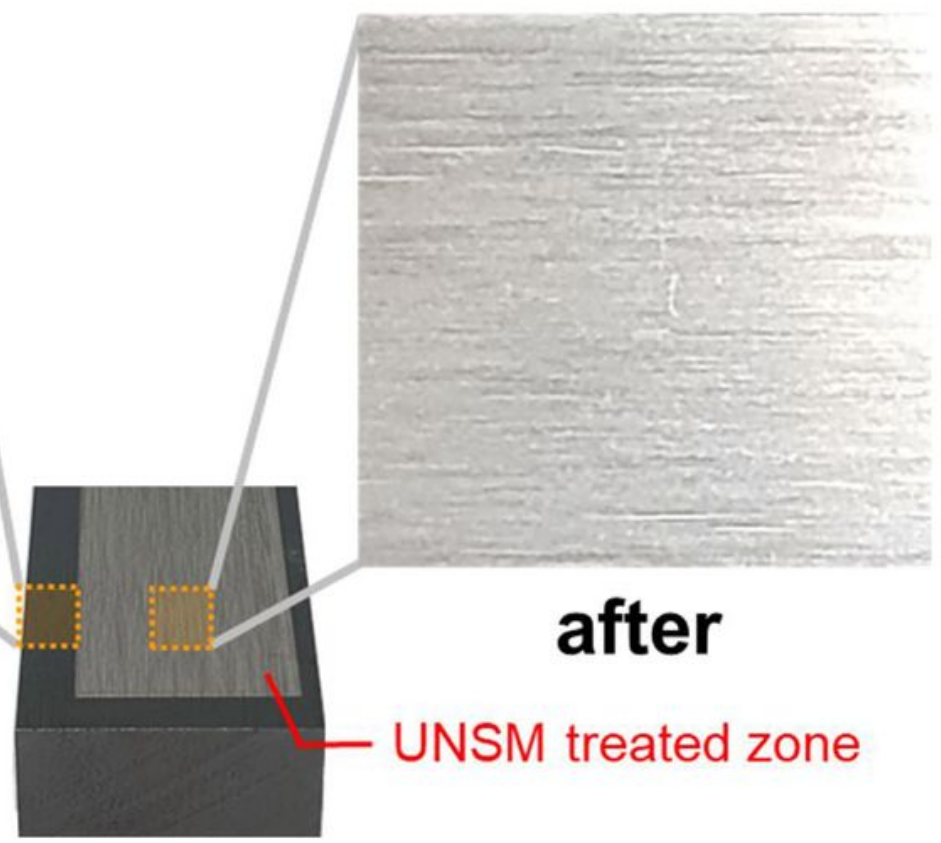

(b)

Figure 4

Photographs of UNSM-treated specimens, and (b) surface change before and after UNSM treatment 

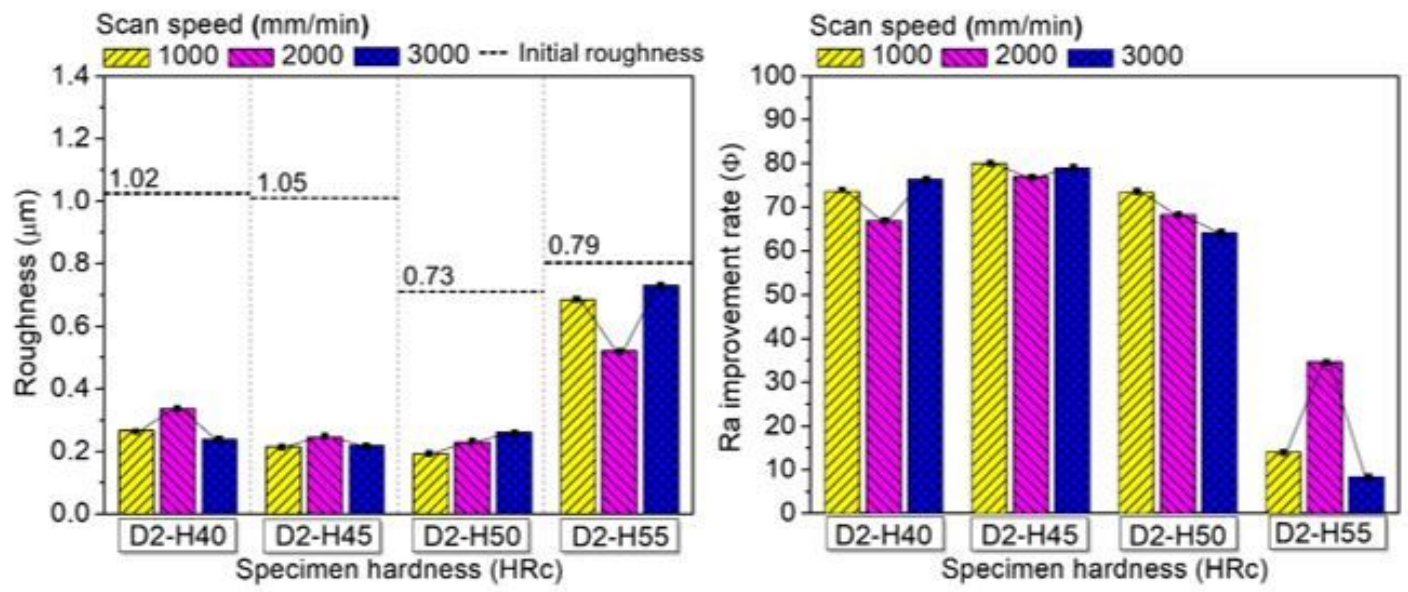

(a)
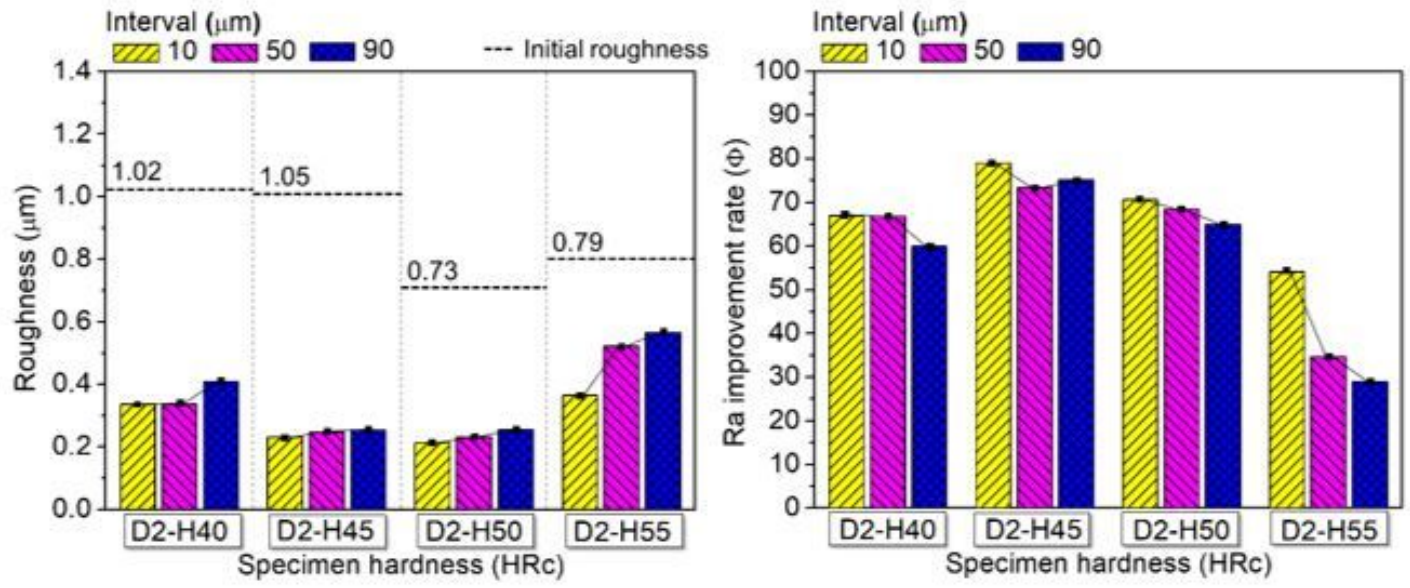

(b)
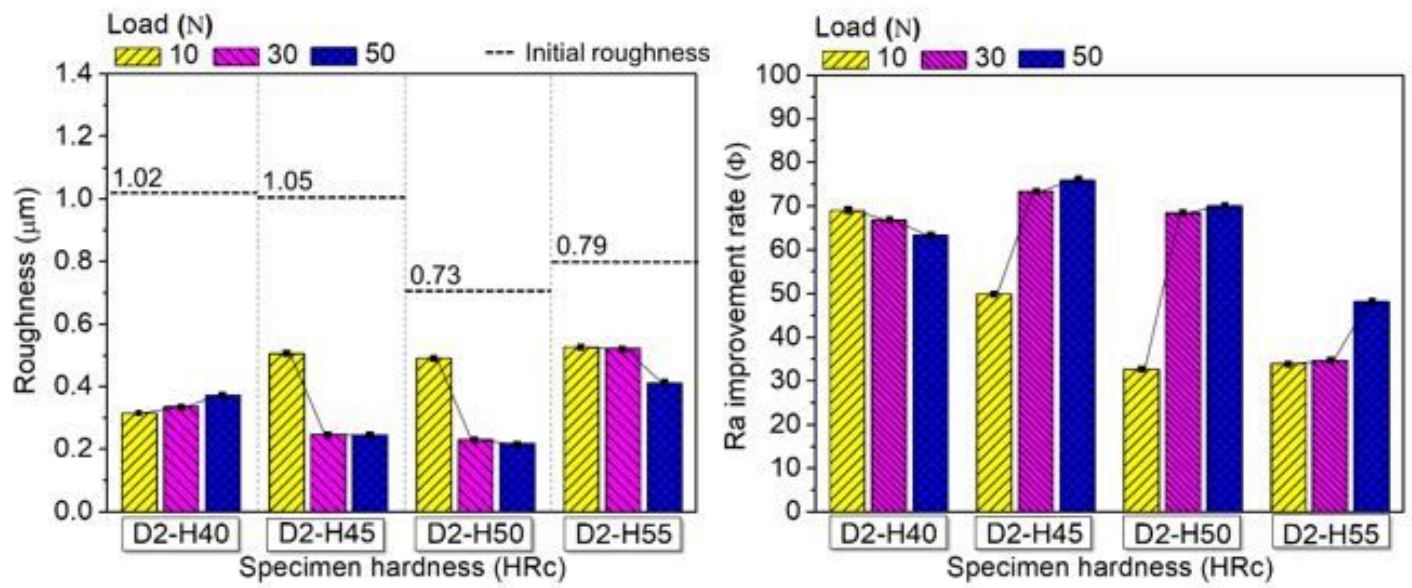

\section{Figure 5}

Comparisons of the surface roughness $(\mathrm{Ra})$ and improvement rate $(\Phi)$ among the specimens with different hardness values according to the UNSM process conditions of (a) feed rate, (b) inter-pass interval, and (c) load 

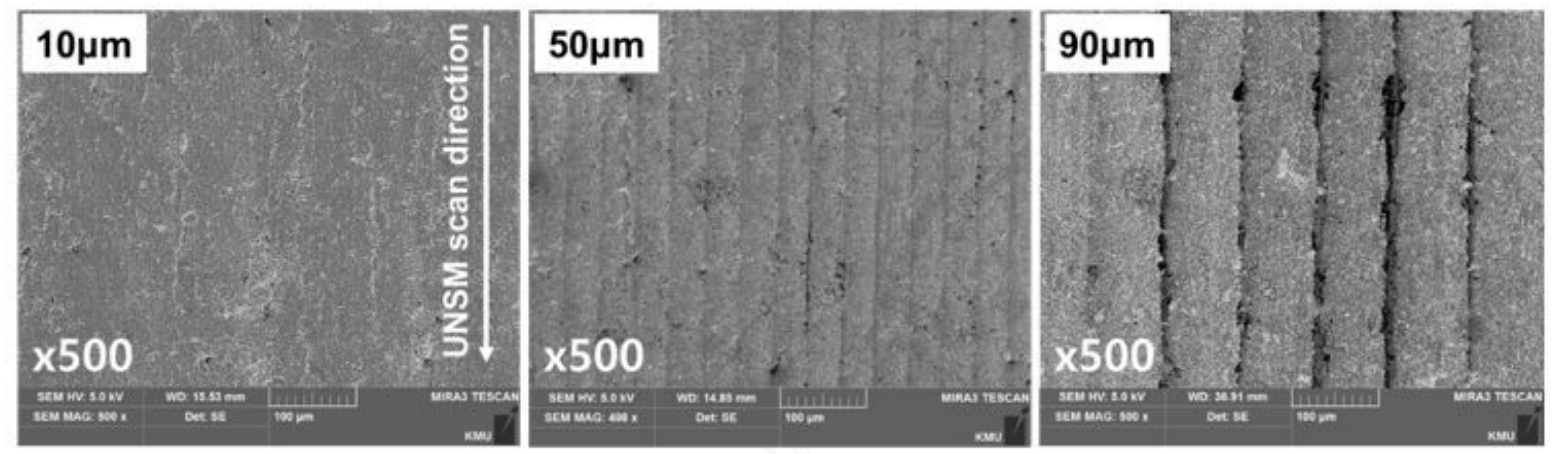

(a)
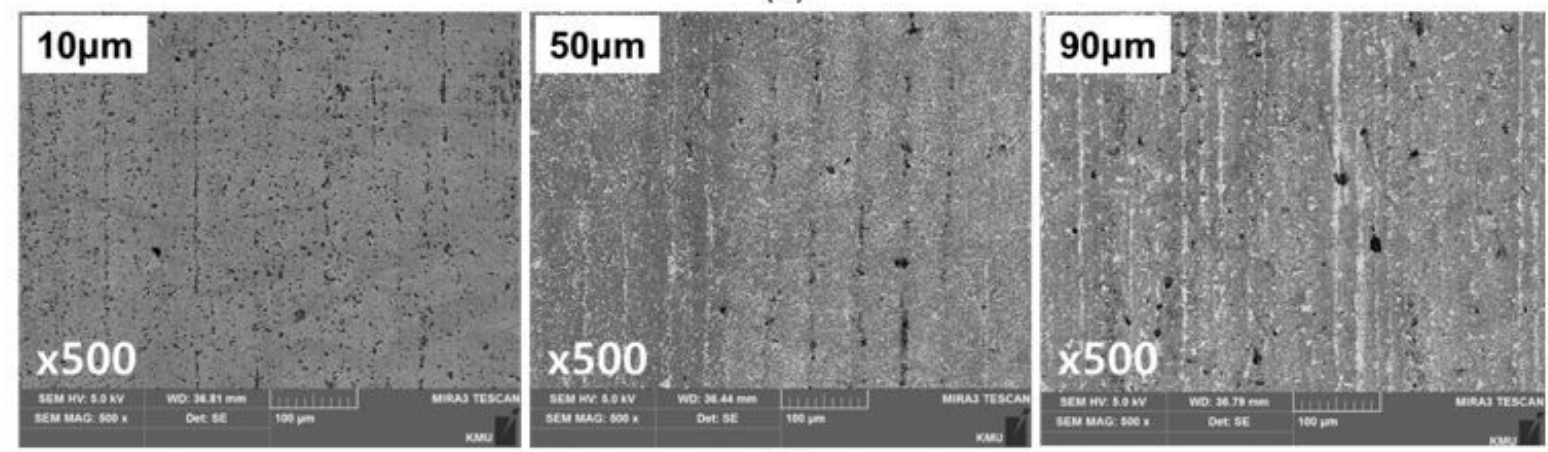

(b)
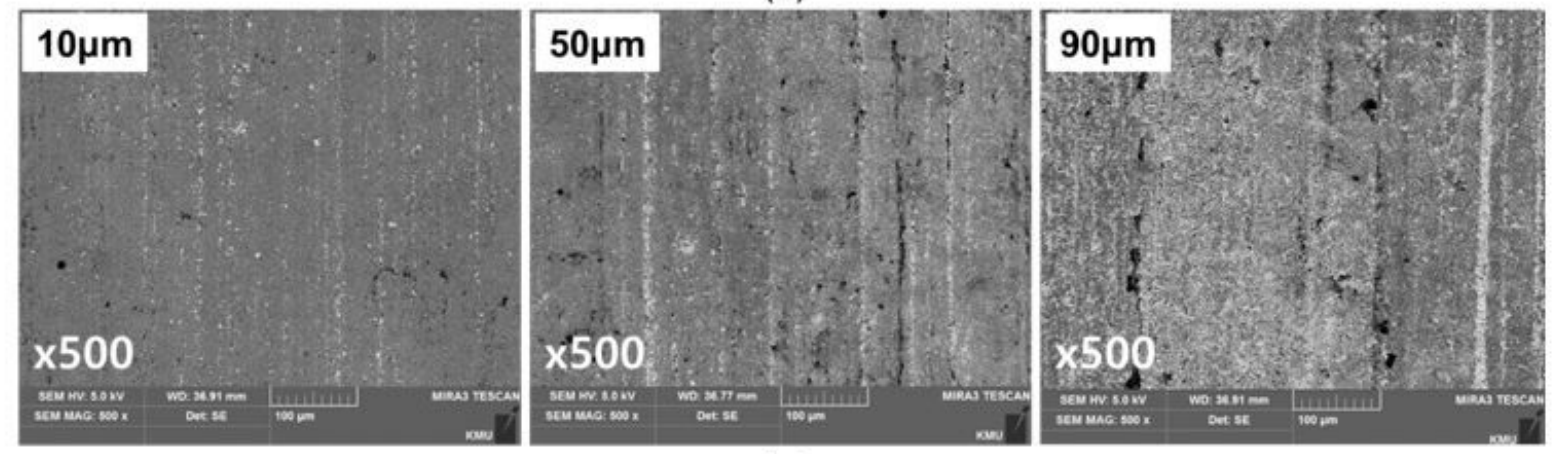

(c)
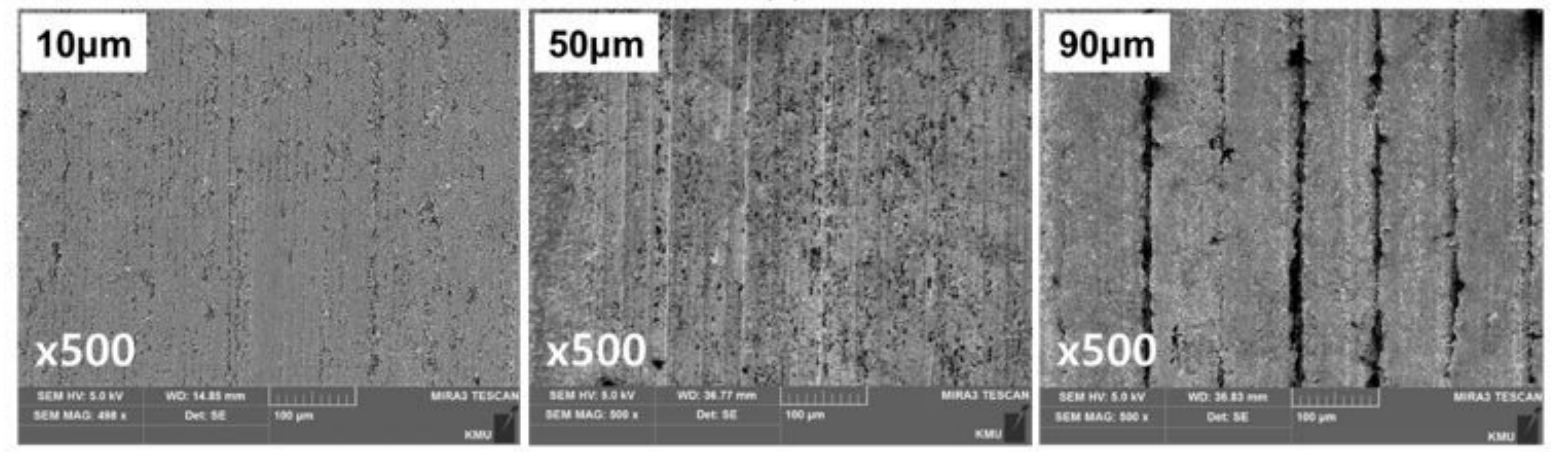

(d)

\section{Figure 6}

Surface SEM images of specimens with different hardness values according to the inter-pass interval of UNSM: (a) D2-H40, (b) D2-H45, (c) D2-H50, and (d) D2-H55 

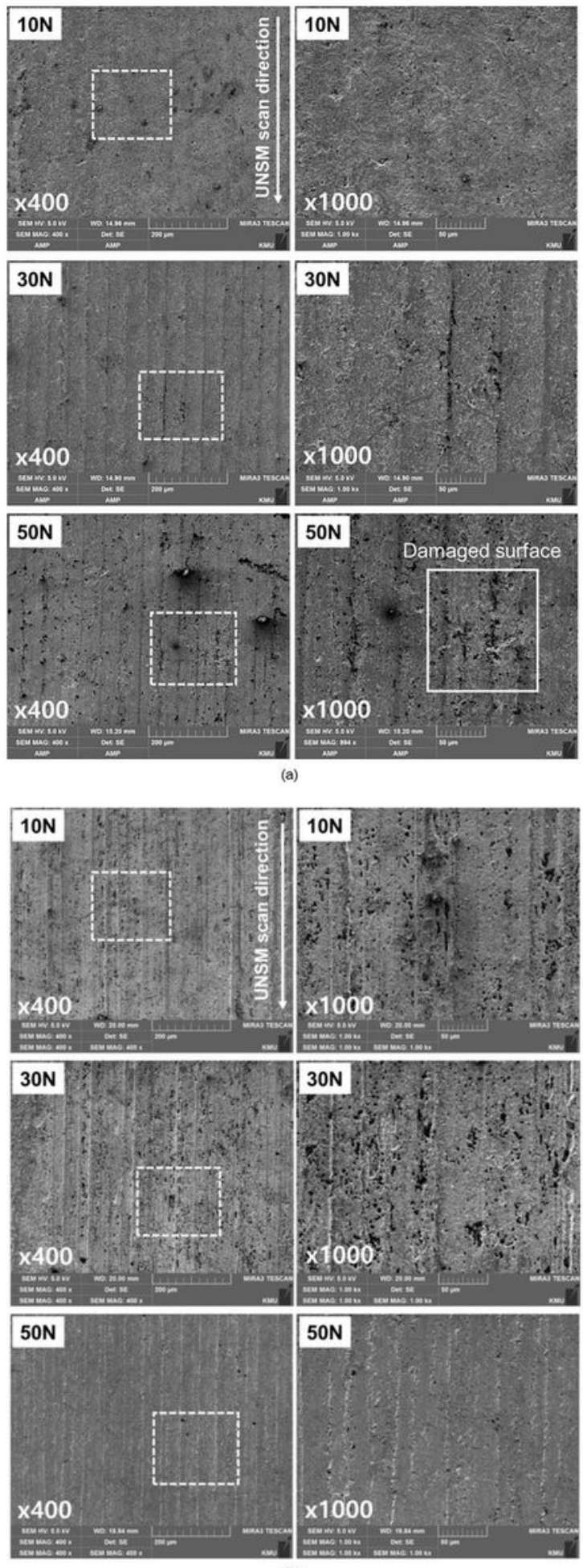

(b)

\section{Figure 7}

Surface images according to the static load; (a) D2-H40, and (b) D2-H45 


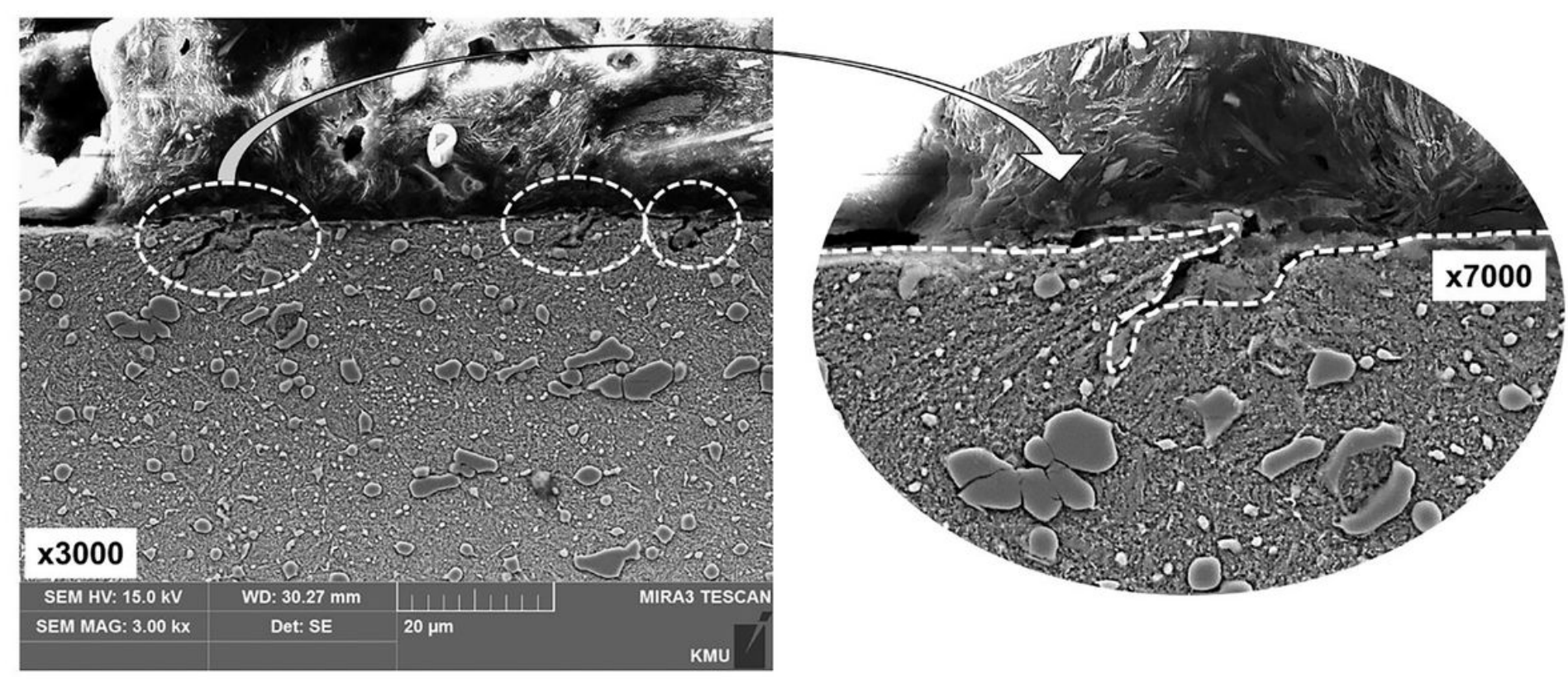

(a)

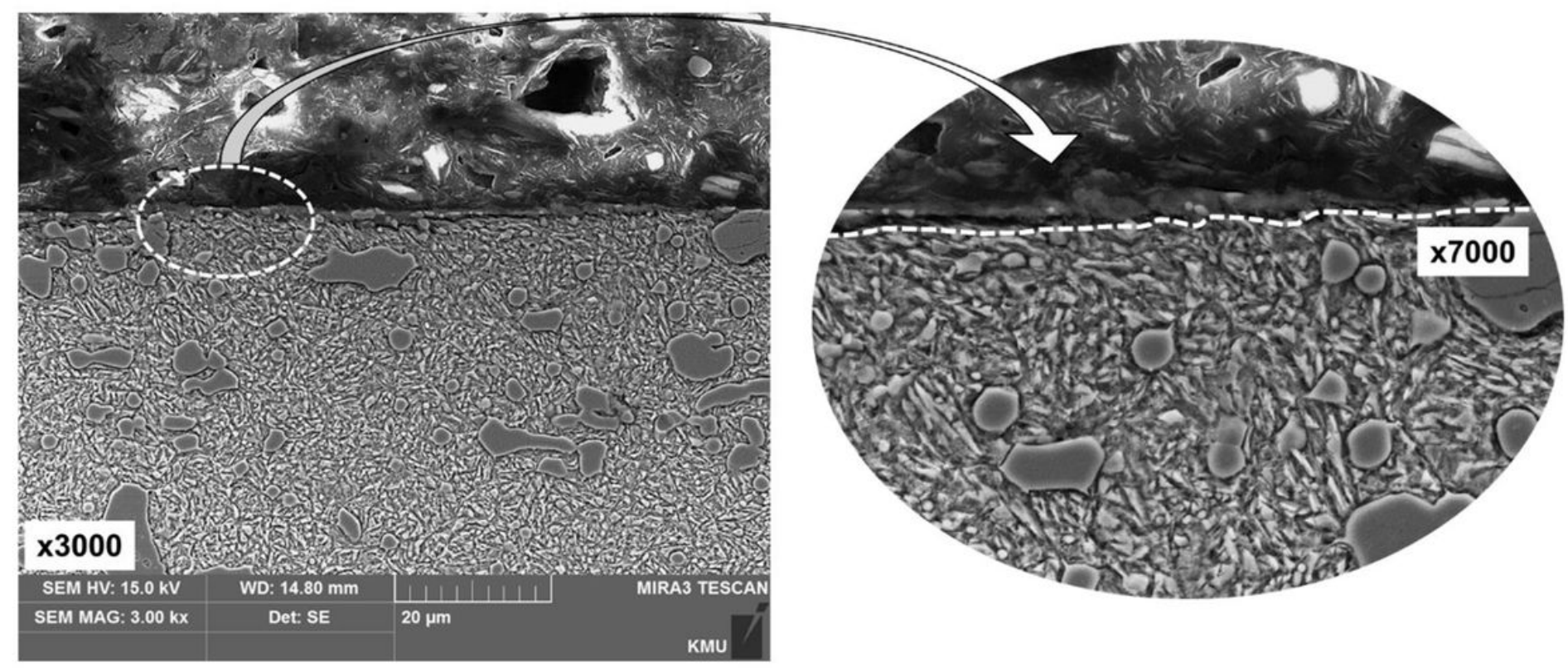

(b)

Figure 8

SEM images of the cross sections near the base metal surfaces under $50 \mathrm{~N}$ : (a) D2-H40, and (b) D2-H55 
Scan speed $(\mathrm{mm} / \mathrm{min})$

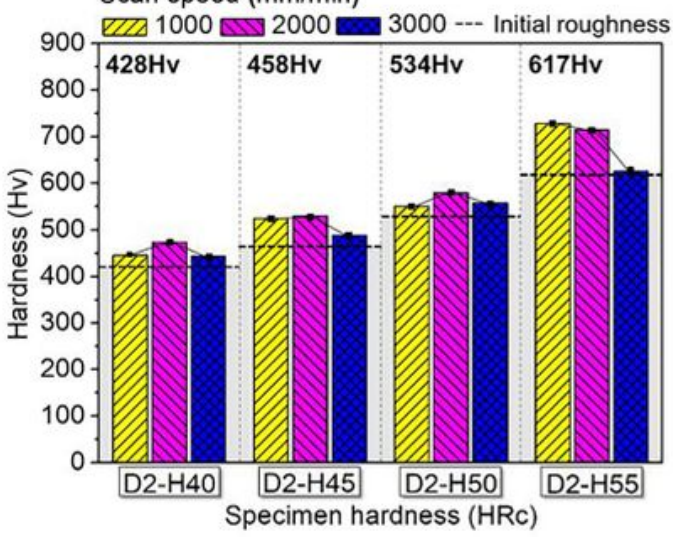

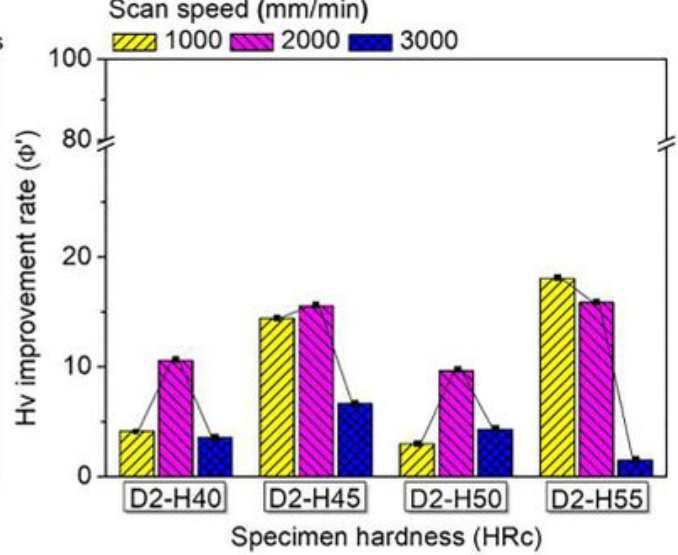

(a)
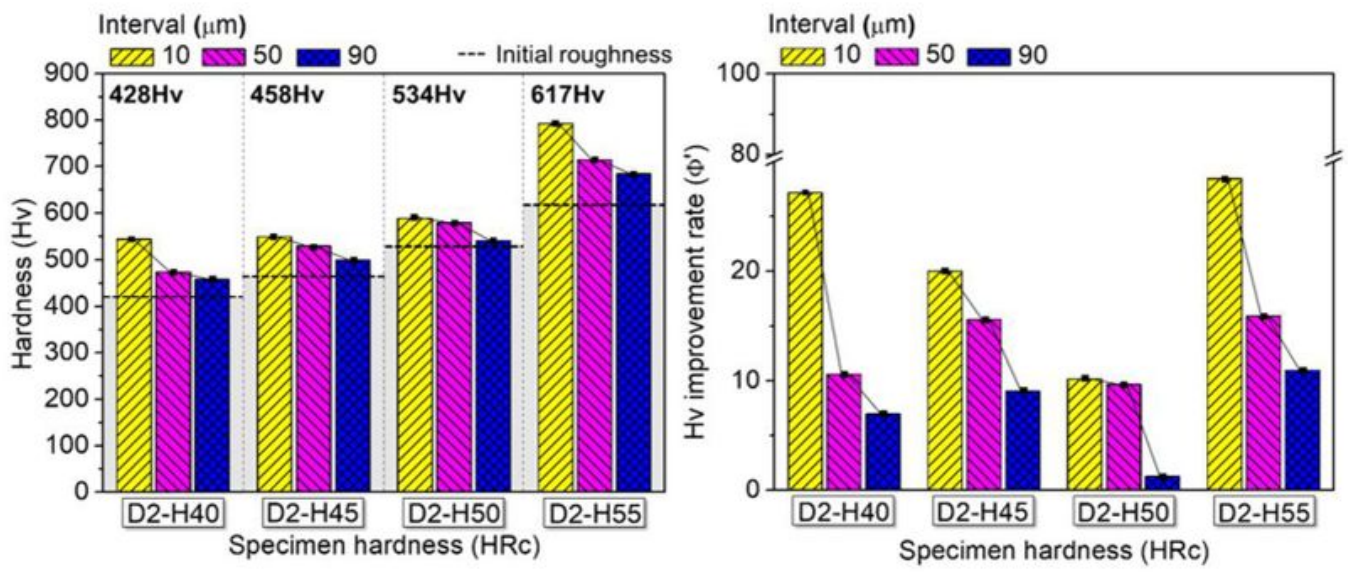

(b)
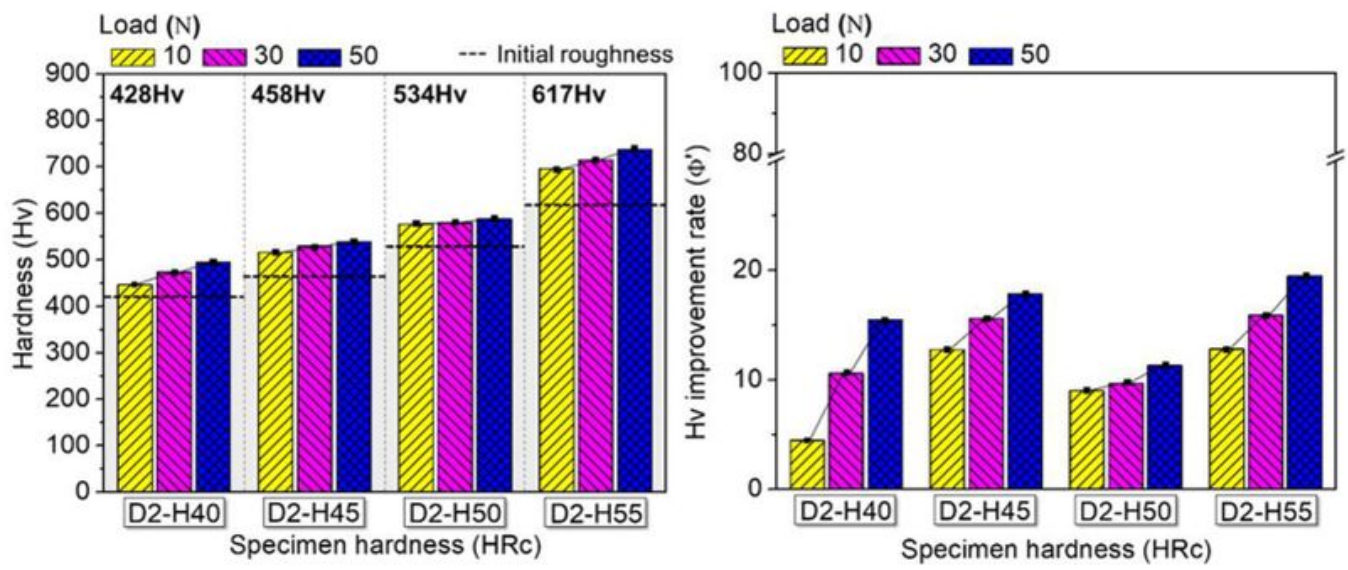

(c)

\section{Figure 9}

Comparisons of the surface hardness and hardness improvement rate $\left(\Phi^{\prime}\right)$ according to the UNSM process conditions of (a) feed rate, (b) inter-pass interval, and (c) load 

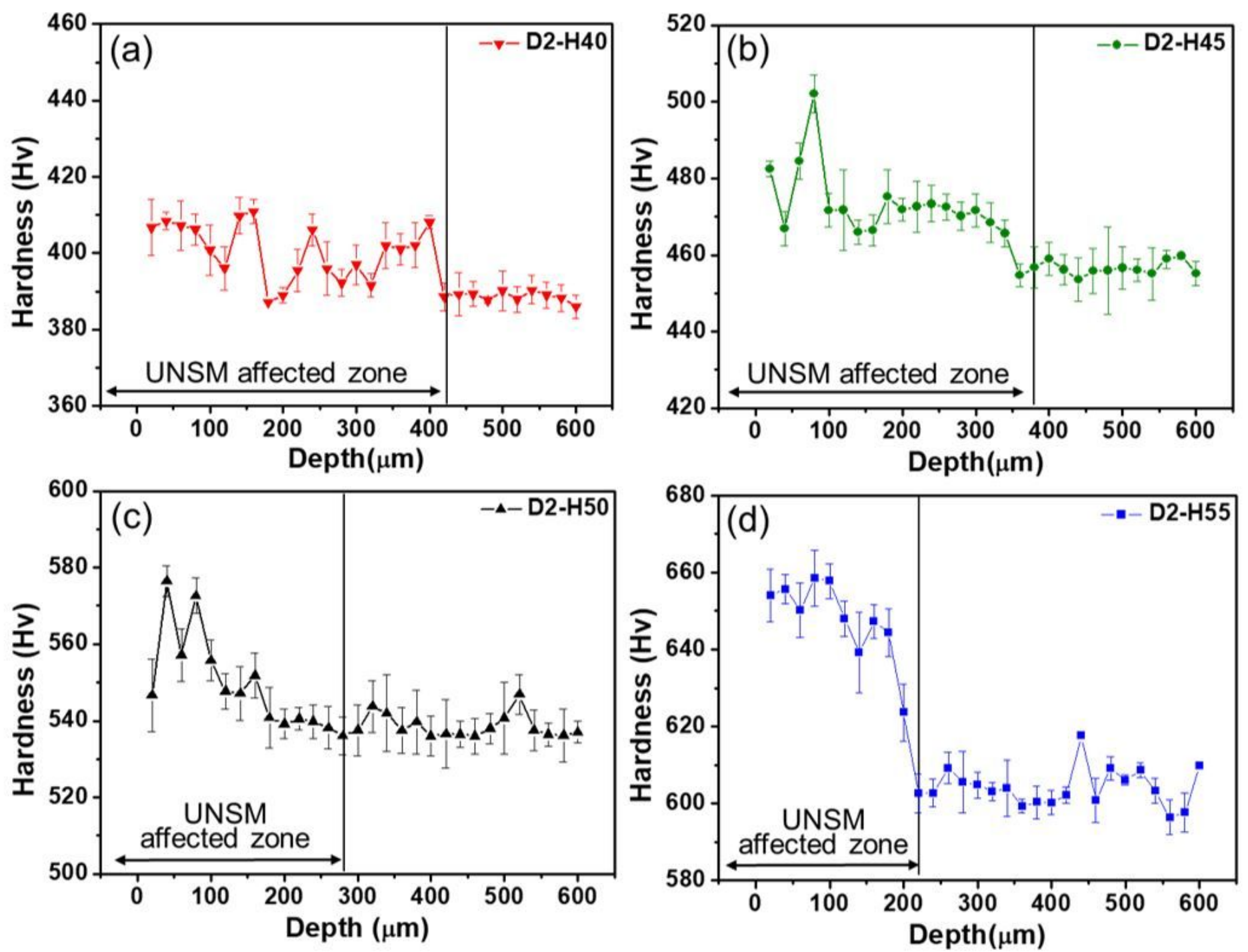

Figure 10

Cross-sectional hardness distribution around the surface; (a) D2-H40, (b) D2-H45, (c) D2-H50, and (d) D2H55 


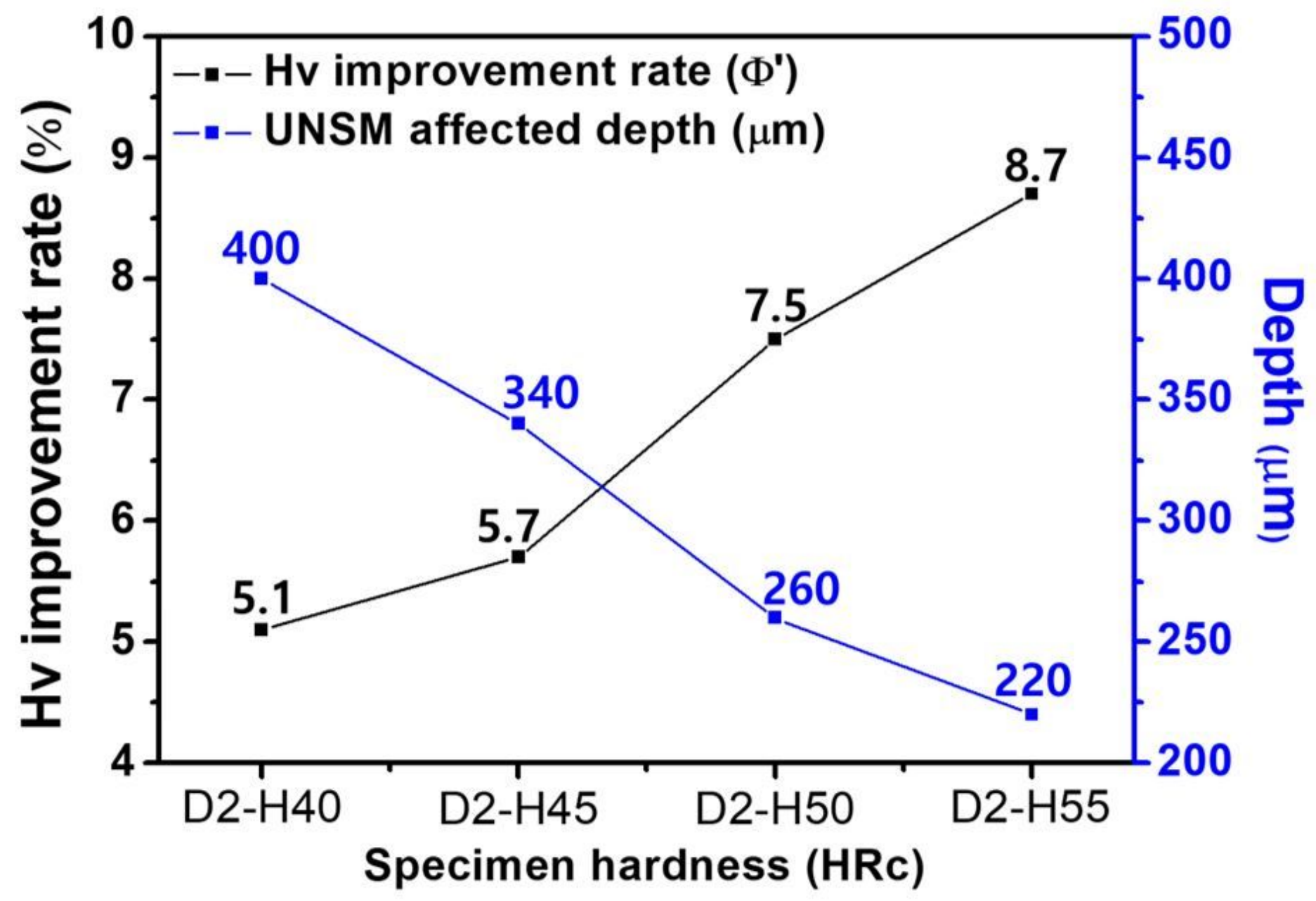

Figure 11

$\Phi^{\prime}$ and UNSM-affected depth according to initial base metal hardness 


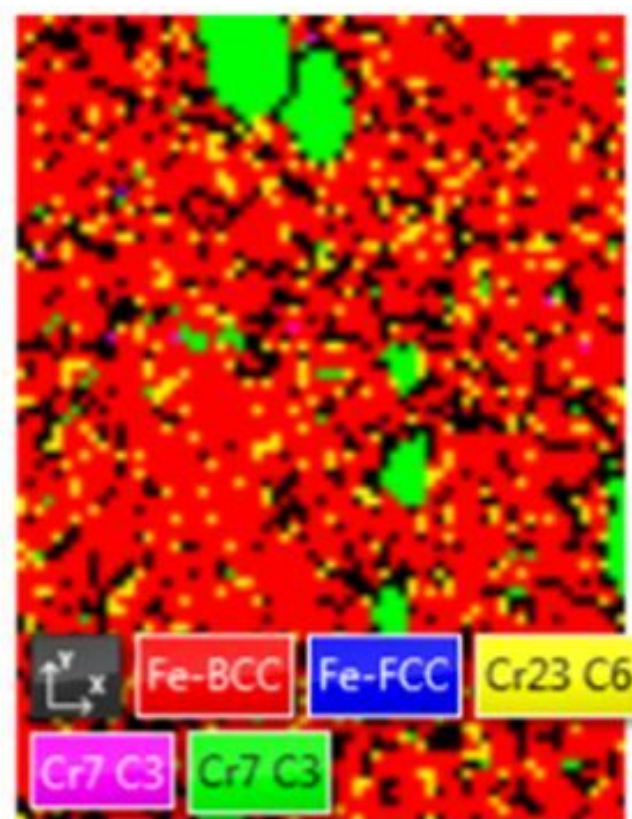

$2.5 \mu \mathrm{m}$

(a)

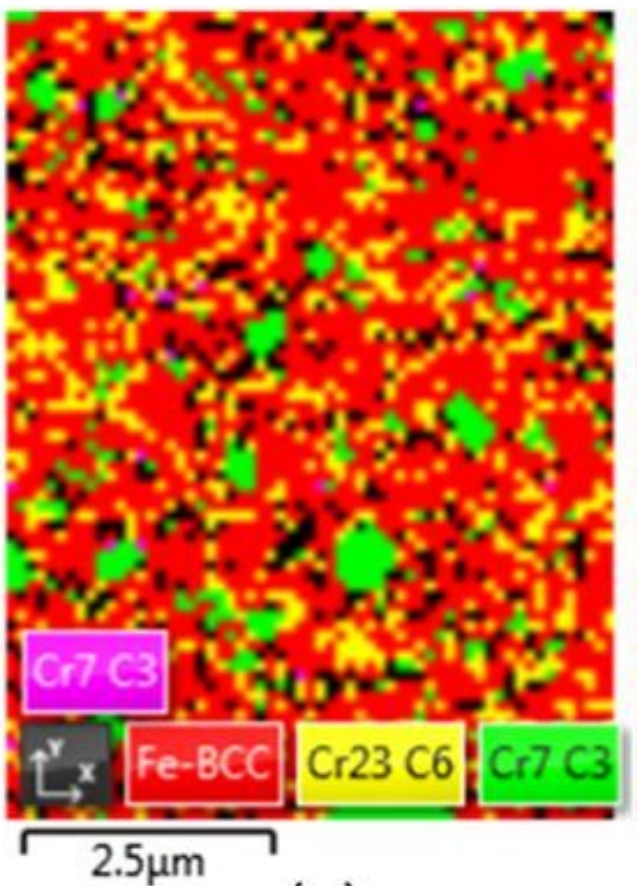

(c)

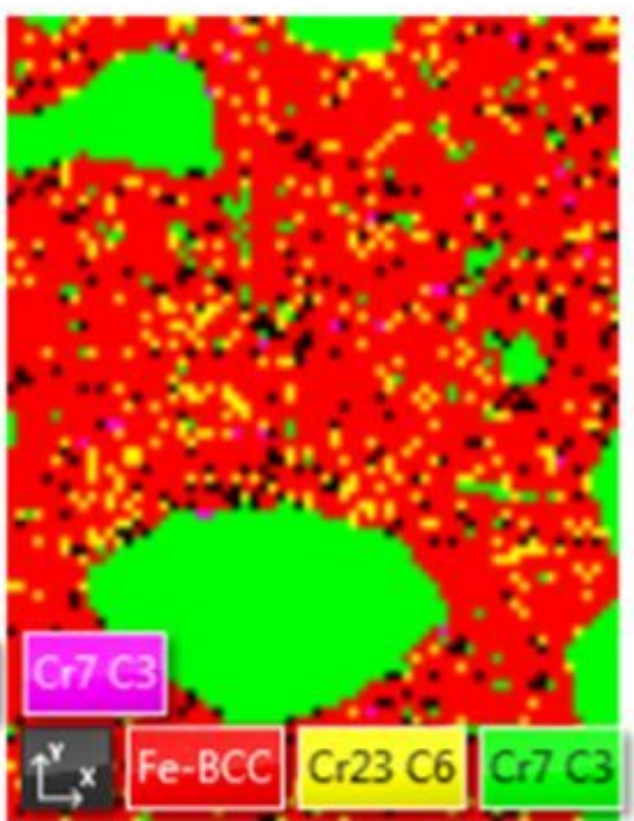

$2.5 \mu \mathrm{m}$

(b)

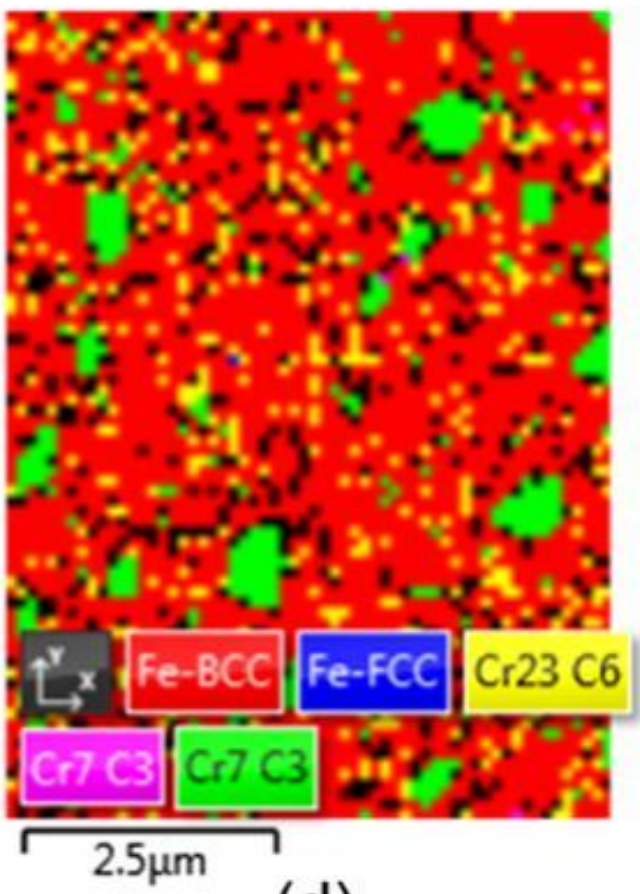

(d)

Figure 12

Phase diagram maps of specimens (a) D2-H40, (b) D2-H45, (c) D2-H50, and (d) D2-H55 

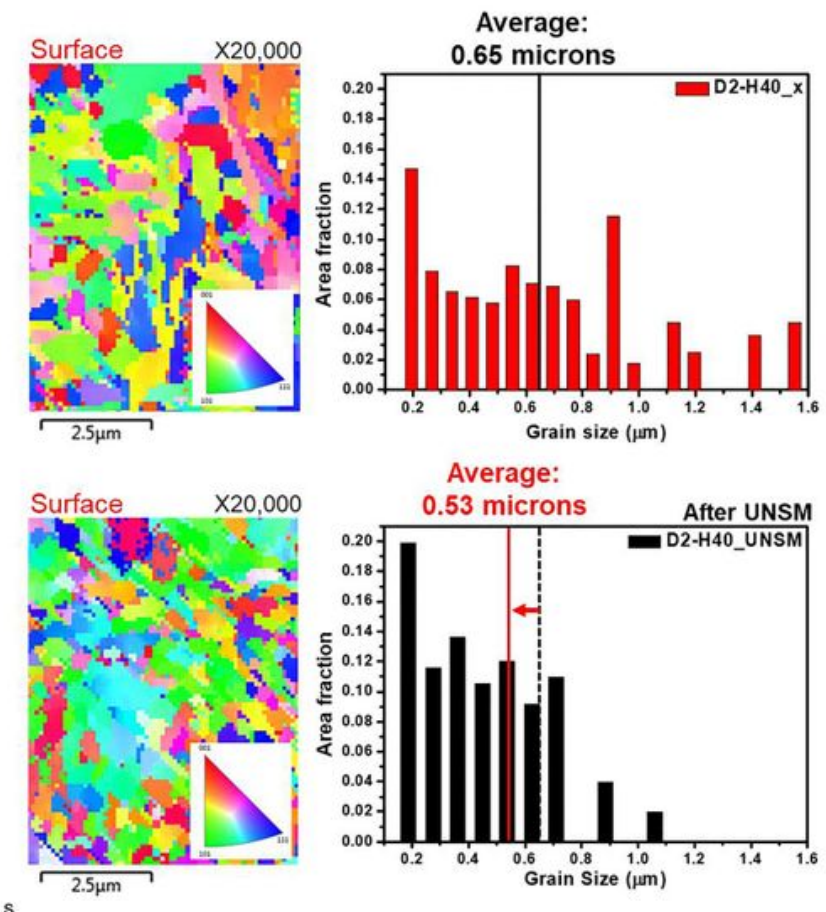

(a)
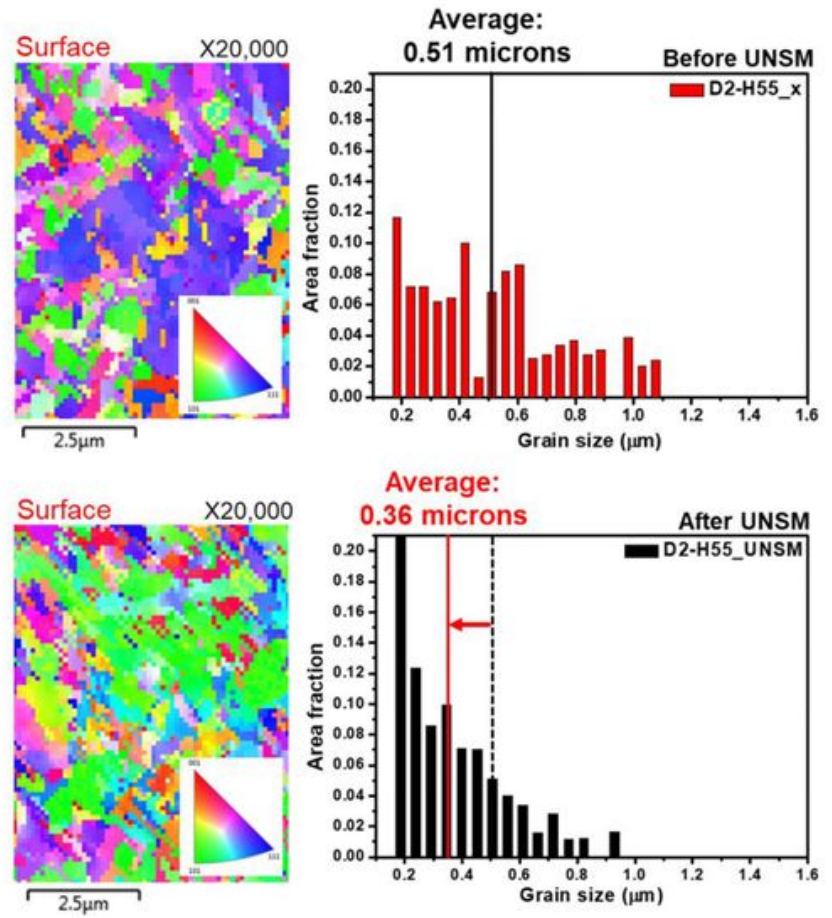

(b)

Figure 13

Inverse pole figures and grain sizes of (a) D2-H40, and (b) D2-H55 before and after UNSM treatment 


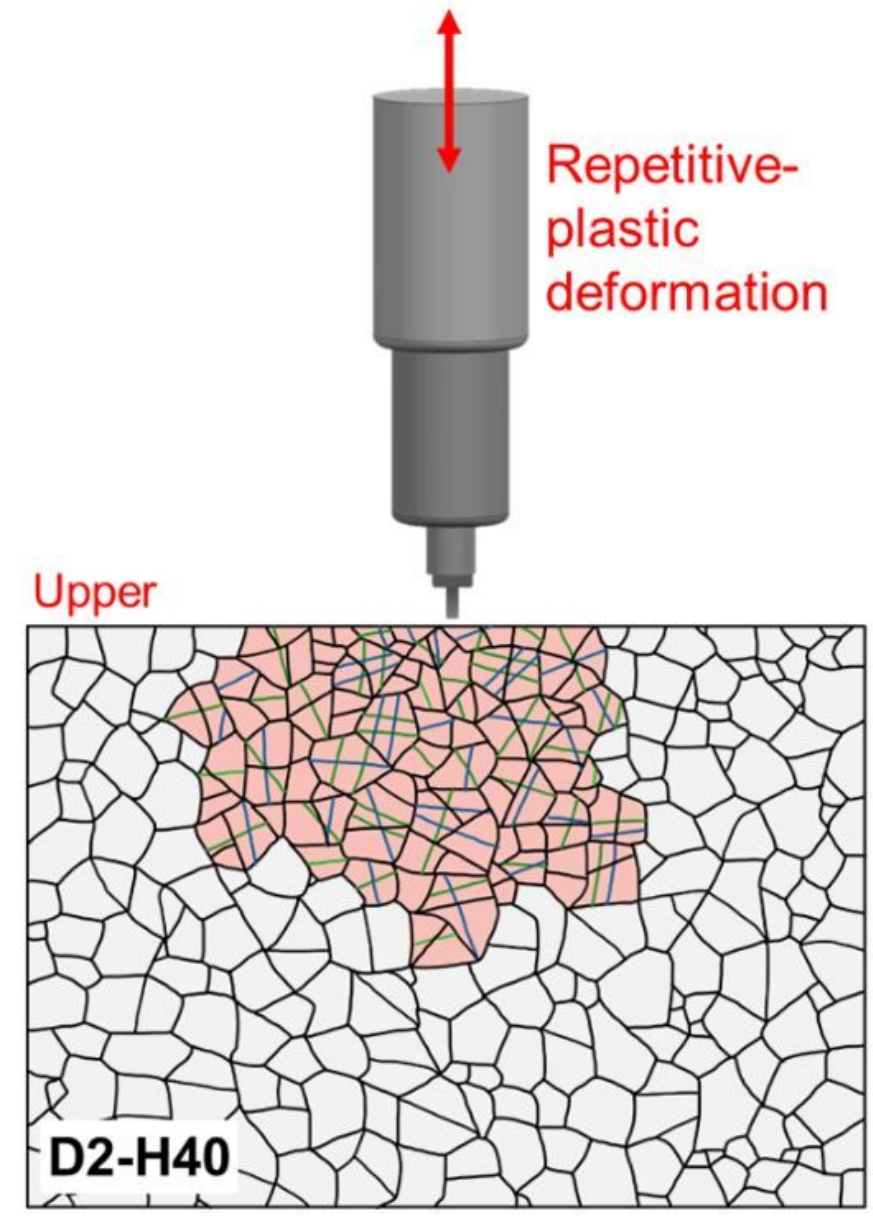

(a)

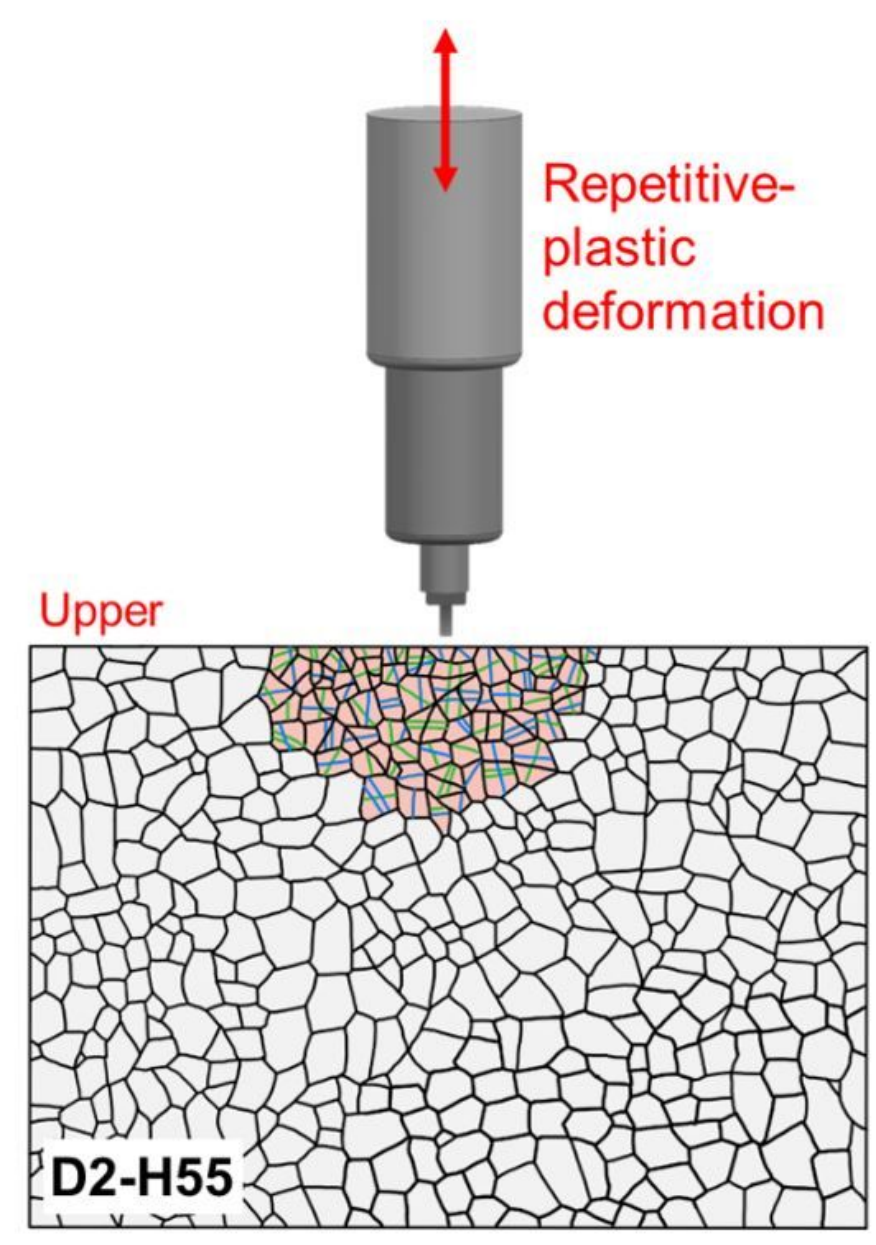

(b)

Figure 14

Schematics of the microstructural changes induced by UNSM in (a) D2-H40, and (b) D2-H55 


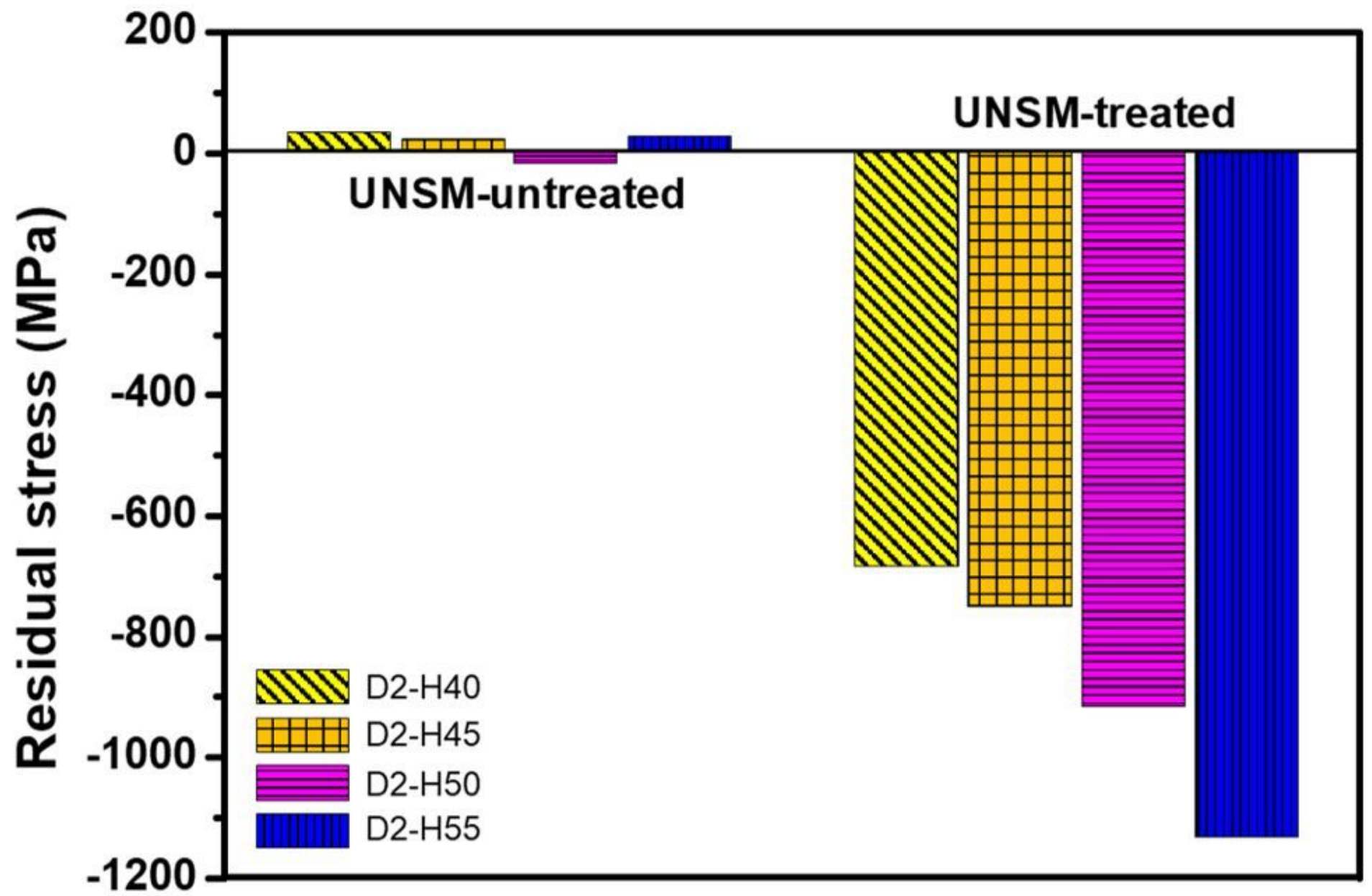

Figure 15

Residual stress before and after UNSM treatment 